\title{
Guia ilustrado de Leguminosae Juss. arbóreas do Corredor de Biodiversidade Santa Maria - PR
}

\author{
Thaís Regina Marcon ${ }^{I, 2}$, Lívia Godinho Temponi ${ }^{1}$, Darlene Gris ${ }^{I}$ \& Andréa Maria Teixeira Fortes ${ }^{I}$ \\ ${ }^{1}$ Centro de Ciências Biológicas e da Saúde, Universidade Estadual do Oeste do Paraná - UNIOESTE, \\ Rua Universitária, 2069, Jd. Universitário, CEP 85819-110, Cascavel, PR, Brasil \\ ${ }^{2}$ Autor para correspondência: Thaís Regina Marcon,e-mail: thaisregina.marcon@gmail.com
}

MARCON, T.R., TEMPONI, L.G., GRIS, D. \& FORTES, A.M.T. Illustrated Guide of Arboreal Leguminosae Juss. in the Corredor de Biodiversidade Santa Maria - PR. Biota Neotrop. 13(3): http://www.biotaneotropica. org.br/v13n3/en/abstract?identification-key+bn03313032013

\begin{abstract}
Leguminosae represents one of the leading families in floristic and phytosociological studies. Such variety can lead to difficulties in identification, particularly in sterile sample collection. The aim of this study was to prepare an illustrated guide with tips from the field, as well as an identification key addressing the major vegetative diagnostic features of Leguminosae trees from the Corredor de Biodiversidade de Santa Maria, which binds the protection strip of Itaipu Lake to the Iguaçu National Park. This corridor brings together several remnants of the Floresta Estacional Semidecidual in south-western Paraná and reforested areas. Samples have been collected in different areas of the corridor, three forest remnants (Iguaçu National Park, the Legal Reserve of Fazenda São José, Private Reserve of Natural Heritage Fazenda Santa Maria), and two reforested areas (Range Dry and Range of Itaipu Lake Protection). Legumes collected were photographed in the field, with prosumer camera, recording morphological and vegetative stem rhytidome, staining the inner bark and/or sapwood, exudate, analysis of the format of the leaflets, the presence of spines, glands, extrafloral nectaries, hairiness, and when present, reproductive structures. The samples were identified and housed at Herbário da Universidade Estadual do Oeste do Paraná (UNOP). Were found 29 species of Leguminosae, for which were designed with guide plates, illustrating the main diagnostic vegetative characteristics, as well as a dichotomous key to assist in the identification of Leguminosae species present in southwestern Paraná. The specimen features trunk as rhytidome, inner bark and/or sapwood, shape and color of the leaflets, presence of exudate, prickles, hairiness, extrafloral nectaries or glands were of great value in the field, which allowed the identification of species of Leguminosae of the Corredor de Biodiversidade Santa Maria.
\end{abstract}

Keywords: identification guide, dichotomous key, Fabaceae, vegetative characters.

MARCON, T.R., TEMPONI, L.G., GRIS, D. \& FORTES, A.M.T. Guia ilustrado de Leguminosae Juss. Arbóreas do Corredor de Biodiversidade Santa Maria - PR. Biota Neotrop. 13(3): http://www.biotaneotropica.org.br/ v13n3/pt/abstract?identification-key+bn03313032013

Resumo: Leguminosae representa uma das principais famílias em estudos florísticos e fitossociológicos. Tal riqueza pode ocasionar dificuldades na identificação, principalmente em coletas de amostras estéreis. O objetivo do presente estudo foi elaborar um guia ilustrado com dicas de campo, bem como uma chave de identificação, abordando as principais características vegetativas diagnósticas das Leguminosae arbóreas do Corredor de Biodiversidade de Santa Maria, o qual une a Faixa de Proteção do Lago de Itaipu ao Parque Nacional do Iguaçu. O corredor reúne vários remanescentes de Floresta Estacional Semidecidual do sudoeste do Paraná e áreas reflorestadas. Foram coletadas amostras em diferentes áreas do corredor, sendo três remanescentes florestais (Parque Nacional do Iguaçu, Reserva Legal da Fazenda São José, Reserva Particular do Patrimônio Natural da Fazenda Santa Maria), e duas áreas reflorestadas (Faixa Seca e Faixa de Proteção do Lago de Itaipu). As Leguminosae coletadas foram fotografadas ainda em campo, com câmera semiprofissional, registrando aspectos morfológicos vegetativos como tronco, ritidoma, coloração da casca interna e/ou alburno, presença de exsudato, formato dos folíolos, presença de acúleos, glândulas, nectários extraflorais, indumento e, quando presentes, estruturas reprodutivas. As amostras foram identificadas e adicionadas ao Herbário da Universidade Estadual do Oeste do Paraná (UNOP). Foram encontradas 29 espécies de Leguminosae, para as quais foi elaborado um guia com pranchas, ilustrando as principais características vegetativas diagnósticas, bem como uma chave dicotômica, a fim de auxiliar na identificação das espécies de Leguminosae presentes no sudoeste do Paraná. Características do tronco como ritidoma, casca interna e/ou alburno, formato e coloração dos folíolos, presença de exsudado, acúleos, indumento, nectários extraflorais ou glândulas foram de grande valia em campo, pois permitiram a identificação das espécies de Leguminosae do Corredor de Biodiversidade de Santa Maria.

Palavras-chave: guia de identificação, chave dicotômica, Fabaceae, caracteres vegetativos. 


\section{Introdução}

A Mata Atlântica, se estendia originalmente por aproximadamente $1.300 .000 \mathrm{~km}^{2}$ em 17 estados do território brasileiro (Campanili \& Schaffer 2010). Atualmente os remanescentes nativos estão reduzidos a cerca de $7,5 \%$ de sua cobertura original, principalmente distribuídos em pequenos fragmentos isolados um dos outros em estágios médios de sucessão (Ribeiro et al. 2009). Mesmo reduzida e muito fragmentada, estima-se que na Mata Atlântica existam cerca de 20.000 espécies vegetais, cerca de $47 \%$ das espécies existentes no Brasil (Forzza et al. 2013), incluindo diversas espécies endêmicas e ameaçadas de extinção. Essa riqueza é maior que a de alguns continentes (17.000 espécies na América do Norte e 12.500 na Europa) e por isso a região da Mata Atlântica é altamente prioritária para a conservação da biodiversidade mundial (Brasil 2013), sendo listada entre os 25 hotspots mundiais (Myers et al. 2000).

O bioma Mata Atlântica abriga três formações florestais, segundo Câmara (1991): Florestas Ombrófilas Densas, Florestas Estacionais Semideciduais ou Deciduais e Florestas Ombrófilas Mistas. As áreas do Corredor de Biodiversidade Santa Maria tem como formação vegetacional predominante a Floresta Estacional Semidecidual, que se desenvolve em clima tropical e subtropical, apresentando dois períodos anuais bem marcados por chuvas e secas (Constantino et al. 2003). Apresenta espécies com folhas decíduas, onde 20 a $50 \%$ das árvores perdem as folhas no período seco - IBGE (Instituto... 2012) o que torna, temporariamente, o interior da floresta mais claro, possibilitando maior proliferação de lianas (Câmara 1991, Ramos et al. 2008) e consequente aumento da biodiversidade local.

As formações florestais encontram-se isoladas e diante desse cenário, destacam-se os corredores de biodiversidade, os quais fazem a conectividade entre remanescentes de ecossistemas naturais, possibilitando a dispersão dos genes da flora e fauna, neutralizando o "efeito ilha", o que pode comprometer a variabilidade genética das espécies (Odum \& Barret 2008, Campanili \& Schaffer 2010). Desta maneira estudos florísticos tanto de áreas preservadas, quanto de fragmentos florestais e corredores de biodiversidade são de suma importância para levantar dados e comparar a ocorrência das espécies em diferentes regiões.

Uma das mais representativas famílias botânicas em estudos florísticos de espécies arbóreas no bioma Mata Atlântica é Leguminosae (Marangon et al. 2003, Rolim et al. 2006, Valério et al. 2008, Jacomassa 2010, Eltink et al. 2011), a qual é cosmopolita e possui a maior riqueza de espécies e ocorrência em quase todas as formações vegetacionais existentes no Brasil (Lewis 1987, Lewis et al. 2005, Lima et al. 2013), mesmo em estudos florísticos de áreas urbanas (Pestana et al. 2011, Snak et al. 2012).

Tamanha diversidade de espécies e ocorrência podem ocasionar dificuldades na identificação dos táxons, especialmente, quando as estruturas reprodutivas não estão presentes. A baixa ocorrência de espécies em estado fértil é frequente durante a realização de trabalhos com vegetação nativa ao longo do ano. Talora \& Morellato (2000) apontam que a floração de muitas espécies arbóreas de florestas tropicais não ocorre com tanta frequência, podendo dificultar a coleta de amostras com caracteres férteis, tradicionalmente utilizados na identificação de espécies vegetais.

Guias ilustrados e chaves dicotômicas de identificação, baseados em características morfológicas vegetativas, são de grande importância no meio científico, pois possibilitam a identificação das espécies em qualquer período do ano, sem a necessidade de estruturas férteis (Eltink et al. 2011). Destacam-se os estudos de Braz et al. (2004), Urbanetz et al. (2010), Eltink et al. (2011) registrados para Mata Atlântica.
Diante dessa importância, o trabalho teve como objetivo facilitar a identificação de Leguminosae arbóreas em campo, através da elaboração de um guia ilustrado e uma chave de identificação, abordando as características vegetativas diagnósticas das espécies dos fragmentos de Mata Atlântica do Corredor de Biodiversidade de Santa Maria.

\section{Material e Métodos}

\section{1. Área de estudo}

O levantamento florístico das espécies de Leguminosae foi realizado no Corredor de Biodiversidade de Santa Maria, o qual visa unir remanescentes de Mata Atlântica do sudoeste do Paraná através da conexão entre áreas governamentais e privadas, que acabaram sendo isoladas pela degradação ambiental - IBAMA (Instituto... 2010).

O Corredor está localizado no sudoeste do Paraná, entre os municípios de Santa Terezinha de Itaipu e São Miguel do Iguaçu. Este corredor tem por objetivo ligar a Faixa de Proteção do Lago de Itaipu ao Parque Nacional do Iguaçu (ParNa Iguaçu), com uma distância de $15 \mathrm{~km}$ entre estas áreas (Itaipu 2010).

O Corredor Santa Maria é formado pela união de fragmentos de Floresta Estacional Semidecidual - IBGE (Instituto... 2012) em diferentes estádios sucessionais e áreas reflorestadas, como demonstrado na Figura 1, obtida com o programa ArcGIS 10 - ESRI (Environment... 2010). Em um dos extremos do corredor encontram-se o Parque Nacional do Iguaçu (PNI), sendo a amostragem realizada na área de junção com o corredor, nas coordenadas $25^{\circ} 53^{\prime} 20.41^{\prime}$ S e 54 29' 09.77'; seguido da Reserva Legal da Fazenda São José (FS), que possui característica de fragmento secundário, localizado nas coordenadas $25^{\circ} 52^{\prime} 51.28^{\prime \prime}$ S e $54^{\circ} 33^{\prime} 37.09^{\prime \prime}$ O de mata ciliar do Rio Apepu; a Reserva Particular do Patrimônio Natural da Fazenda Santa Maria (FT), a qual é uma floresta nativa madura que abrange um território de 242 ha, situada nas coordenadas $25^{\circ} 49^{\prime} 19.89^{\prime \prime} \mathrm{S}$ e $54^{\circ} 36^{\prime} 00.55^{\prime \prime} \mathrm{O}$; e matas ciliares que margeiam o Rio Bonito (FI), consideradas como fragmentos iniciais, localizado nas coordenadas $25^{\circ} 45^{\prime} 88.06^{\prime}$ ' S e $54^{\circ} 35^{\prime} 40.00^{\prime \prime} \mathrm{O}$, com aproximadamente 30 ha, e que sofreram intensa degradação e atualmente passam por um processo de recuperação florestal natural. Além destes fragmentos naturais, o corredor inclui uma área reflorestada em 2003, representada pela Faixa Seca, um fragmento reflorestado inicial (FRi) assim chamado por ser uma área reflorestada da largura de uma mata ciliar (60 m), mas não apresentar curso d'água em sua extensão de, aproximadamente, $4 \mathrm{~km}$, localizado entre as coordenadas $25^{\circ} 48^{\prime}$ 24.34" S e 54 $35^{\circ}$ '46.26" O e no outro extremo do corredor a mata ciliar do Lago de Itaipu (FRt), implantada em 1979 no entorno do reservatório, com 2,9 mil quilômetros de extensão e uma largura média de $217 \mathrm{~m}$, entre as coordenadas $25^{\circ} 40^{\prime} 23.03^{\prime \prime}$ e $54^{\circ} 39^{\prime} 46.50^{\prime \prime}$.

\section{Coleta e identificação das espécies}

As coletas de Leguminosae arbóreas foram realizadas mensalmente, no período de um ano, entre julho de 2011 e julho de 2012, em 54 parcelas permanentes de $20 \times 20 \mathrm{~m}$, previamente marcadas para trabalhos de fitossociologia, distribuídas entre as seis áreas ao longo do Corredor de Biodiversidade Santa Maria, totalizando uma área amostral com cerca de 2,2 ha.

Analisou-se o tronco e o ritidoma de cada indivíduo, observando as características da casca externa, como aparência, presença ou ausência de acúleos ou lenticelas. Para observações da casca interna e/ou alburno, tanto no quesito coloração quanto presença de exsudato, foram feitos cortes tangenciais ao eixo longitudinal dos troncos de cada uma das espécies ilustradas. 


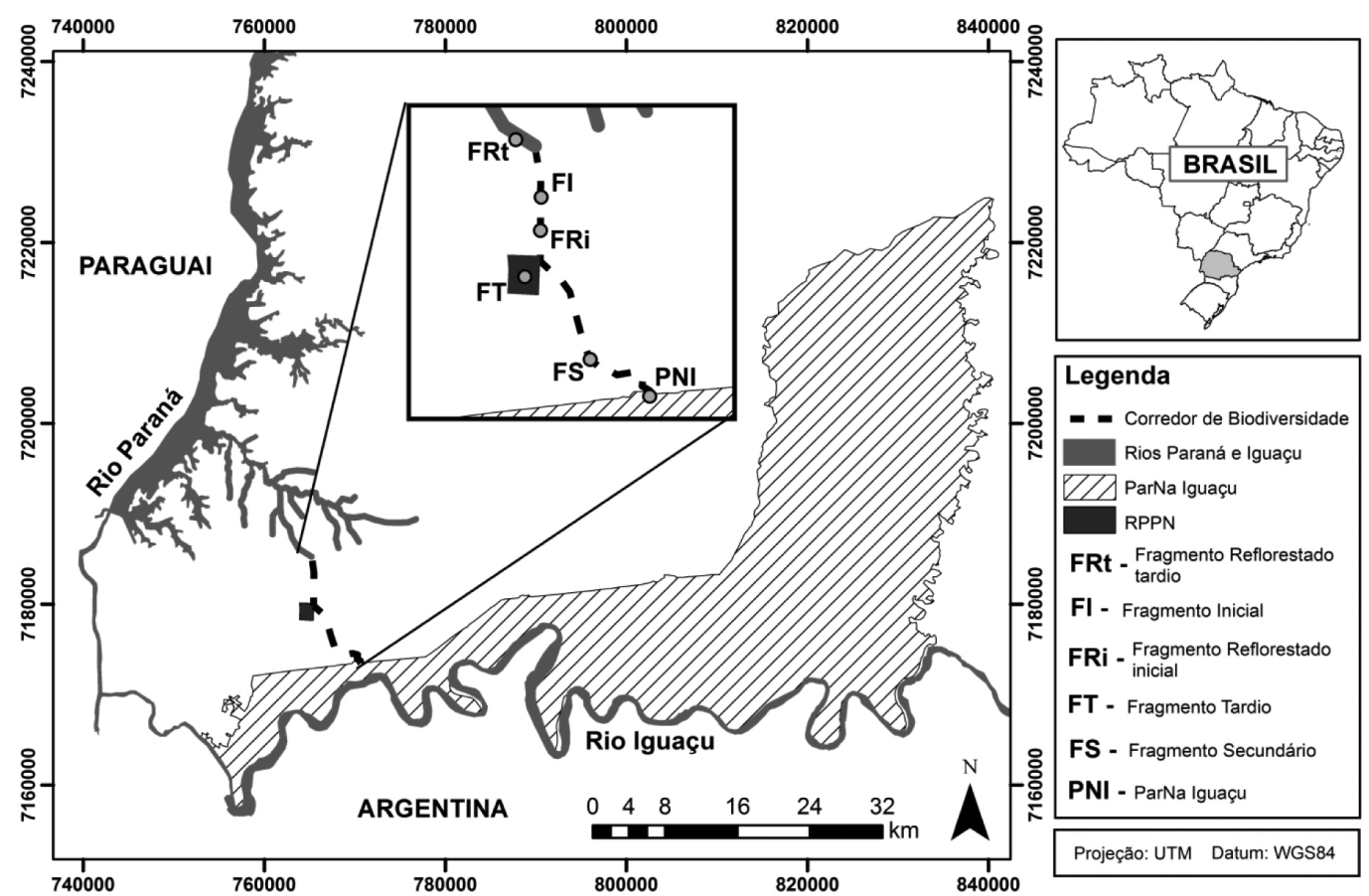

Figura 1. Área do Corredor de Biodiversidade Santa Maria, ligando a faixa de proteção na borda do Lago de Itaipu (FRt) ao Parque Nacional do Iguaçu (PNI). Fonte: ArcGIS 10 ESRI - (Environment... 2010).

Figure 1. Area of Corredor de Biodiversidade Santa Maria, connecting the protective strip on the edge of Lago de Itaipu (FRt) to the Parque Nacional do Iguaçu (PNI). Source: ArcGIS 10 ESRI - (Environment... 2010).

As amostras foram fotografadas com câmera semiprofissional Canon EOS Rebel T1i, ainda em campo, registrando características vegetativas das espécies, como ramos, folhas, folíolos, além de características diagnósticas, como glândulas, nectários extraflorais, acúleos, espinhos, indumento, entre outras. Para cada fotografia foi utilizada uma escala de tamanho, representada por régua escolar azul de $20 \mathrm{~cm}$ ou papel quadriculado em escala de $1 \mathrm{~cm}$.

O guia de identificação das espécies foi construído através das fotografias realizadas em campo, as quais foram editadas no programa Corel PHOTO-PAINT X5 e montadas em prancha no programa CorelDRAW X5. Com análise de cada uma das espécies e seleção dos caracteres diagnósticos, uma chave de identificação foi elaborada, utilizando caracteres vegetativos de fácil observação e diagnósticos para cada uma das espécies.

Nas amostras férteis retrataram-se também os caracteres reprodutivos, flores e frutos, neste caso o material coletado foi preparado seguindo a metodologia de Bridson \& Forman (2004), para incorporação no Herbário Estadual do Oeste do Paraná (UNOP).

As identificações das espécies basearam-se em chaves analíticas e consultas a bibliografias específicas (Barneby 1991, Sartori \& Tozzi 2004, Carvalho 2003, 2006, Ramos et al. 2008, Silva \& Tozzi 2012a, b), comparação das exsicatas em herbários e auxílio de especialistas, quando necessário.

A terminologia dos caracteres morfológicos gerais seguiram Gonçalves \& Lorenzi (2011). Para morfologia e disposição dos folíolos utilizou-se Radford et al. (1974) e Ash et al. (1999). As características do tronco, ritidoma, casca interna e presença de exsudato foram classificadas segundo Ribeiro et al. (1999) e os nomes dos autores das espécies estão de acordo com a Lista de Espécies da Flora do Brasil (Lima et al. 2013) ou o International Plant Name Index - IPNI (International... 1999).

\section{Resultados e Discussão}

Foram observadas 29 espécies de Leguminosae na área de estudo, distribuídas em 24 gêneros, sendo apenas uma das espécies exótica do Brasil e 28 nativas. O número de espécies foi maior que o de outros levantamentos de arbóreas em Mata Atlântica, os quais listaram 11 espécies (Braz et al. 2004), cinco (Valério et al. 2008), 22 (Dionísio et al. 2010), 14 (Jacomassa 2010) e 16 espécies de Leguminosae (Eltink et al. 2011), comprovando a diversidade de ambientes na área estudada, além da eficiência do esforço amostral efetuado no presente estudo. Em áreas mais amplas, um número ainda maior (67) foi registrado apenas para espécies de Papilionoideae com diferentes hábitos de vida (Silva \& Tozzi 2012a), refletindo a grande riqueza de espécies da família.

As espécies coletadas podem ser reconhecidas pela chave de identificação (Anexo 1), pelas dicas de campo da Tabela 1 e pelas Figuras 2-16, onde estão ilustradas as principais características morfológicas das espécies encontradas.

A maioria das espécies encontradas possuem tronco único, exceto Mimosa bimucronata (DC.) Kuntze que caracteriza-se pela capacidade de produzir diversos troncos, chamada assim de planta cespitosa (Ribeiro et al. 1999).

Quanto ao aspecto do tronco encontrado nas espécies coletadas, o circular teve maior ocorrência, porém para algumas espécies foram encontrados troncos com aspecto acanalado, quando a secção é irregular com depressões e elevações longitudinais encontrado em Holocalyx balansae Micheli (Figura 7g) e Machaerium stipitatum Vogel (Figura 11a), cristado definido por apresentar projeções longitudinais agudas na forma de cristas ou arestas, observado em Anadenanthera peregrina var. falcata (Benth.) Altschul. (Figura 2a) e Piptadenia gonoacantha (Mart.) J.F.Macbr. (Figura 13g). 
Leguminosae Juss. arbóreas do Corredor de Biodiversidade Santa Maria - PR

Tabela 1. Lista das espécies de Leguminosae encontradas ao longo do Corredor de Biodiversidade de Santa Maria com seus respectivos nomes populares, números das fotos com as pranchas de cada espécie e características vegetativas diagnósticas, Cascavel - PR, 2012.

Table 1. List of Leguminosae species found along the Corredor de Biodiversidade de Santa Maria with their popular names, numbers of photos with illustrated boards of each species and vegetative diagnostic characteristics, Cascavel - PR, 2012.

\begin{tabular}{|c|c|c|}
\hline Espécie/ nome popular & Figura/voucher & Dicas de campo \\
\hline $\begin{array}{l}\text { Anadenanthera peregrina var. } \\
\text { falcata (Benth.) Altschul./ } \\
\text { angico-do-cerrado }\end{array}$ & $\begin{array}{l}\text { Figura } 2 \mathrm{a}-\mathrm{f} \\
\text { UNOP } 7963\end{array}$ & $\begin{array}{l}\text { Tronco fortemente cristado com projeções em forma pontiagudas, casca interna laranja- } \\
\text { amarelada, nectário extrafloral elíptico na base do pecíolo. }\end{array}$ \\
\hline $\begin{array}{l}\text { Apuleia leiocarpa (Vogel) } \\
\text { J.F.Macbr./ grápia }\end{array}$ & $\begin{array}{l}\text { Figura } 2 \mathrm{~g}-\mathrm{k} \\
\text { UNOP } 6730\end{array}$ & $\begin{array}{l}\text { Ritidoma com depressões (cicatrizes arredondadas), casca interna com anéis laranja- } \\
\text { rosado, ramo com folíolos alternos discolores, variando de oval, elíptico, oblongo } \\
\text { a oboval, sendo os apicais maiores que os basais, face abaxial com nervura central } \\
\text { amarela evidente. }\end{array}$ \\
\hline $\begin{array}{l}\text { Bauhinia forficata Link./ } \\
\text { pata-de-vaca }\end{array}$ & $\begin{array}{l}\text { Figura } 3 a-g \\
\text { UNOP } 7326 \\
\text { UNOP } 5458\end{array}$ & $\begin{array}{l}\text { Ritidoma com estrias ou sulcos rasos, folíolos discolores bilobados fundidos até } \\
\text { próximo à região mediana da raque, face abaxial com nervuras evidentes, pares de } \\
\text { acúleos na inserção dos ramos. }\end{array}$ \\
\hline $\begin{array}{l}\text { Calliandra foliolosa Benth./ } \\
\text { quebra-foice }\end{array}$ & $\begin{array}{l}\text { Figura } 3 \text { h-o } \\
\text { UNOP } 7343\end{array}$ & $\begin{array}{l}\text { Casca interna com fibras de coloração rosa e esbranquiçada, ramos e folhas com } \\
\text { indumento claro, estípulas foliáceas castanhas e com indumento. }\end{array}$ \\
\hline $\begin{array}{l}\text { Cassia leptophylla Vogel/ } \\
\text { falso-barbatimão }\end{array}$ & $\begin{array}{l}\text { Figura } 4 a-d \\
\text { UNOP } 4846\end{array}$ & $\begin{array}{l}\text { Casca interna e alburno esbranquiçados, ramo com indumento, folhas imparipinadas, } \\
\text { folíolos opostos elípticos concolores, com ápice agudo e base assimétrica, face abaxial } \\
\text { com nervura central amarela evidente. }\end{array}$ \\
\hline $\begin{array}{l}\text { Copaifera langsdorffii } \\
\text { Desf./ copaíba }\end{array}$ & $\begin{array}{l}\text { Figura } 4 \text { e-j } \\
\text { MBM } 186785\end{array}$ & $\begin{array}{l}\text { Tronco jovem com ritidoma com estrias vermelhas e maduro com alburno } \\
\text { esbranquiçado e exsudato vermelho, folíolos subopostos, apicais maiores que os } \\
\text { basais, ápice arredondado, levemente retuso e base obtusa, glândulas translúcidas em } \\
\text { forma de pontos no limbo. }\end{array}$ \\
\hline $\begin{array}{l}\text { Dahlstedtia muehlbergiana } \\
\quad \text { (Hassl.) M.J.Silva \& } \\
\text { A.M.G.Azevedo / timbó-graúdo }\end{array}$ & $\begin{array}{l}\text { Figura } 5 \mathrm{a}-\mathrm{f} \\
\text { UNOP } 7329\end{array}$ & $\begin{array}{l}\text { Ritidoma escamoso, casca interna amarelada, folíolos discolores com ápice acuminado } \\
\text { e base obtusa a arredondada, face abaxial com nervuras centrais e laterais evidentes. }\end{array}$ \\
\hline $\begin{array}{l}\text { Dalbergia frutescens (Vell.) } \\
\text { Britton/ rabo-de-bugio }\end{array}$ & $\begin{array}{l}\text { Figura } 5 g-m \\
\text { UNOP } 7952\end{array}$ & $\begin{array}{l}\text { Tronco reto, com hábito escandente, ritidoma rugoso, casca interna esbranquiçada, } \\
\text { ramo escandente torcido, folíolos ovais a elípticos, ápice obtuso a acuminado e base } \\
\text { obtusa, face adaxial lustrosa e abaxial opaca puberulenta. }\end{array}$ \\
\hline $\begin{array}{l}\text { Enterolobium contortisiliquum } \\
\text { (Vell.) Morong/ timbaúva }\end{array}$ & $\begin{array}{l}\text { Figura } 6 a-g \\
\text { UNOP } 4879\end{array}$ & $\begin{array}{l}\text { Ritidoma com lenticelas, alburno rosado, nectários extraflorais arredondados entre os } \\
\text { pares de folíolos levemente discolores, planta totalmente glabra. }\end{array}$ \\
\hline $\begin{array}{l}\text { Erythrina falcata } \text { Benth./ } \\
\text { mulungu, corticeira }\end{array}$ & $\begin{array}{l}\text { Figura } 6 h-1 \\
\text { UNOP } 7958\end{array}$ & $\begin{array}{l}\text { Ritidoma com sulcos profundos, par de nectários extraflorais na inserção dos folíolos, } \\
\text { folíolos discolores, elípticos a oblongos, ápice acuminado e base arredondada, nervura } \\
\text { central evidente na face abaxial, ramo com folhas trifolioladas. }\end{array}$ \\
\hline $\begin{array}{l}\text { Gleditsia amorphoides } \\
\text { (Griseb.) Taub./ sucará }\end{array}$ & $\begin{array}{l}\text { Figura 7a-f } \\
\text { UNOP } 7967\end{array}$ & $\begin{array}{l}\text { Ritidoma rugoso com lenticelas e espinhos ramificados e alburno esbranquiçado, três } \\
\text { gemas acessórias axiais na inserção das folhas, ramo com folhas pinadas e bipinadas, } \\
\text { folíolos com bordas crenadas, forma e tamanho irregulares, bordas crenadas. }\end{array}$ \\
\hline $\begin{array}{l}\text { Holocalyx balansae } \\
\text { Micheli/ alecrim }\end{array}$ & $\begin{array}{l}\text { Figura } 7 g-j \\
\text { UNOP } 7964\end{array}$ & $\begin{array}{l}\text { Tronco acanalado com reentrâncias, casca interna rosada em indivíduo maduro e } \\
\text { esbranquiçada em jovens, ramo com folhas pinadas, folíolos estreitamente elípticos } \\
\text { com base assimétrica e nervura actinódroma. }\end{array}$ \\
\hline $\begin{array}{l}\text { Inga marginata Willd./ } \\
\text { ingá-feijão }\end{array}$ & $\begin{array}{l}\text { Figura 8a-g } \\
\text { UNOP } 7959\end{array}$ & $\begin{array}{l}\text { Casca interna rosada, folíolos elípticos, ápice acuminado e base aguda, raque alada } \\
\text { com nectário extrafloral arredondado, entre os pares de folíolos glabros. }\end{array}$ \\
\hline $\begin{array}{l}\text { Inga striata } \text { Benth./ } \\
\text { ingá-de-folha-peluda }\end{array}$ & $\begin{array}{l}\text { Figura } 8 \text { h-1 } \\
\text { UNOP } 8120\end{array}$ & $\begin{array}{l}\text { Casca interna amarela-rosada, indumento castanho na raque alada e nas nervuras, } \\
\text { uma nectário extrafloral arredondado entre cada par de folíolos, folíolos discolores, } \\
\text { elíptico-ovado, ápice agudo e base obtusa, face abaxial mais clara com nervura evidente. }\end{array}$ \\
\hline $\begin{array}{l}\text { Leucaena leucocephala } \\
\text { (Lam.) de Wit/ leucena }\end{array}$ & $\begin{array}{l}\text { Figura 9a-g } \\
\text { UNOP } 4893\end{array}$ & $\begin{array}{l}\text { Ritidoma com lenticelas em linhas verticais, casca interna rosada e alburno fibroso } \\
\text { amarelado, nectário extrafloral vistoso e arredondado na porção apical do pecíolo, } \\
\text { folíolos discolores. }\end{array}$ \\
\hline $\begin{array}{l}\text { Lonchocarpus cultratus (Vell.) } \\
\text { A.M.G.Azevedo \& H.C.Lima / } \\
\text { rabo-de-bugio }\end{array}$ & $\begin{array}{l}\text { Figura } 9 h-1 \\
\text { MBM } 342286\end{array}$ & $\begin{array}{l}\text { Casca interna amarelada, folíolos opostos apicais elípticos e folíolos basais ovais, } \\
\text { folíolos com ápice acuminado e discolores, face abaxial tomentosa com nervura } \\
\text { central amarela evidente. }\end{array}$ \\
\hline $\begin{array}{l}\text { Machaerium nyctitans (Vell.) } \\
\text { Benth./ mau-vizinho }\end{array}$ & $\begin{array}{l}\text { Figura 10a-f } \\
\text { MBM } 251208\end{array}$ & $\begin{array}{l}\text { Ritidoma com sulcos profundos sem desprendimento evidente, ramo com espinhos aos } \\
\text { pares, indumento castanho nos folíolos alternos, raque e nervuras, folíolos oblongos } \\
\text { com ápice e base arredondados. }\end{array}$ \\
\hline $\begin{array}{l}\text { Machaerium paraguariense } \\
\text { Hassl./ farinha-seca }\end{array}$ & $\begin{array}{l}\text { Figura } 10 \mathrm{~g}-\mathrm{k} \\
\text { UNOP } 7962\end{array}$ & $\begin{array}{l}\text { Ritidoma escamoso, casca interna rosa com exsudato vermelho, folíolos ovais, ápice } \\
\text { acuminado e base arredondada, face abaxial com nervura central evidente. }\end{array}$ \\
\hline $\begin{array}{l}\text { Machaerium stipitatum } \\
\text { Vogel/ sapuva }\end{array}$ & $\begin{array}{l}\text { Figura 11a-f } \\
\text { UNOP } 4867\end{array}$ & $\begin{array}{l}\text { Tronco acanalado, ritidoma escamoso, casca interna marrom com exsudato vermelho } \\
\text { e alburno branco, tronco jovem com casca interna vermelha e exsudato vermelho, } \\
\text { folíolos apicais elípticos e basais ovais, ápice agudo a emarginado e base obtusa a aguda. }\end{array}$ \\
\hline
\end{tabular}


Marcon, T.R. et al.

Tabela 1. Continuação...

Table 1. Continued...

\begin{tabular}{|c|c|c|}
\hline Espécie/ nome popular & Figura/ voucher & Dicas de campo \\
\hline $\begin{array}{l}\text { Mimosa bimucronata } \\
\text { (DC.) Kuntze/ maricá }\end{array}$ & $\begin{array}{l}\text { Figura } 11 g-1 \\
\text { UNOP } 7956\end{array}$ & $\begin{array}{l}\text { Planta cespitosa, ritidoma com sulcos profundos, sem desprendimento evidente e } \\
\text { com acúleos, casa interna esbranquiçada e fibrosa, ramo com estípula persistente, } \\
\text { folhas bipinadas. }\end{array}$ \\
\hline $\begin{array}{l}\text { Myroxylon peruiferum } \\
\text { L. f./ bálsamo }\end{array}$ & $\begin{array}{l}\text { Figura 12a-e } \\
\text { MBM } 243563\end{array}$ & $\begin{array}{l}\text { Casca interna compacta branca, folíolos alternos elípticos a ovais, ápice emarginado } \\
\text { e base arredondada, face abaxial com nervura central amarela evidente, das glândulas } \\
\text { translúcidas em forma de traços no limbo. }\end{array}$ \\
\hline $\begin{array}{l}\text { Parapiptadenia rigida (Benth.) } \\
\text { Brenan/ angico-da-mata }\end{array}$ & $\begin{array}{l}\text { Figura } 12 \mathrm{f}-\mathrm{k} \\
\text { UNOP } 7955\end{array}$ & $\begin{array}{l}\text { Ritidoma desprendendo-se em placas em indivíduo maduro, casca interna compacta } \\
\text { rosada, nectário extrafloral elíptico na base do pecíolo. }\end{array}$ \\
\hline $\begin{array}{l}\text { Peltophorum dubium (Spreng.) } \\
\text { Taub./ canafístula }\end{array}$ & & $\begin{array}{l}\text { Ritidoma com sulcos profundos sem desprendimento evidente, casca interna rosa } \\
\text { a avermelhada, indumento castanha na raque e em ramos jovens, estípula foliácea. }\end{array}$ \\
\hline $\begin{array}{l}\text { Piptadenia gonoacantha (Mart.) } \\
\text { J.F.Macbr./ pau-jacaré }\end{array}$ & $\begin{array}{l}\text { Figura } 13 g-m \\
\text { UNOP } 7299\end{array}$ & $\begin{array}{l}\text { Tronco cristado, ritidoma e com lâminas perpendiculares, casca interna esbranquiçada, } \\
\text { ramo com acúleos, nectários extraflorais arredondados no início do pecíolo e no último } \\
\text { par de folíolos. }\end{array}$ \\
\hline $\begin{array}{l}\text { Poincianella pluviosa (DC.) } \\
\text { L.P.Queiroz/ sibipiruna }\end{array}$ & $\begin{array}{l}\text { Figura } 14 \mathrm{a}-\mathrm{g} \\
\text { UNOP } 4465\end{array}$ & $\begin{array}{l}\text { Tronco circular, ritidoma rugoso, casca interna esbranquiçada, gemas globosas com } \\
\text { indumento castanho. }\end{array}$ \\
\hline Pterogyne nitens Tul./ amendoim & $\begin{array}{l}\text { Figura 15a-e } \\
\text { MBM } 257182\end{array}$ & $\begin{array}{l}\text { Ritidoma com lenticelas dispersas, alburno com estrias rosa-esbranquiçadas, folhas } \\
\text { terminando em apêndice na raque, folíolos elípticos a oblongos, ápice arredondado e } \\
\text { base obtusa, face abaxial com nervura central evidente. }\end{array}$ \\
\hline $\begin{array}{l}\text { Schizolobium parahyba (Vell.) } \\
\text { S.F. Blake/ guapuruvu }\end{array}$ & $\begin{array}{l}\text { Figura } 15 f-k \\
\text { UNOP } 7961\end{array}$ & $\begin{array}{l}\text { Ritidoma rugoso com cicatrizes horizontais da inserção das folhas, alburno rosado e } \\
\text { estriado, ramos jovens clorofilados, folha com até } 1 \mathrm{~m} \text { de comprimento, indumento } \\
\text { viscoso nos ramos, raque e folíblulos. }\end{array}$ \\
\hline $\begin{array}{l}\text { Senegalia polyphylla (DC.) } \\
\text { Britton \& Rose/ monjoleiro }\end{array}$ & $\begin{array}{l}\text { Figura } 16 a-h \\
\text { UNOP } 8118\end{array}$ & $\begin{array}{l}\text { Ritidoma rugoso com acúleos, casca interna vermelha em indivíduos maduros e } \\
\text { esbranquiçada em jovem, acúleos também presentes na raque, nectário extrafloral } \\
\text { circular a oval na base do pecíolo e nectário extrafloral arredondado entre os pares } \\
\text { de folíolos apicais. }\end{array}$ \\
\hline $\begin{array}{c}\text { Senegalia recurva (Benth.) } \\
\text { Seigler \& Ebinger/ angico-preto }\end{array}$ & $\begin{array}{l}\text { Figura } 16 i-p \\
\text { UNOP } 7966\end{array}$ & $\begin{array}{l}\text { Tronco circular com sulcos profundos e sem desprendimento evidente, casca interna } \\
\text { compacta e esbranquiçada, acúleos nos ramos e na raque, um nectário extrafloral } \\
\text { alongado no pecíolo e arredondado entre } 3 \text { a } 6 \text { pares de folíolos apicais. }\end{array}$ \\
\hline
\end{tabular}

O ritidoma liso não apresenta nenhuma forma de desprendimento, fissuras ou lenticelas e de maneira geral são exceções na floresta e nenhuma das espécies estudadas apresentou esse tipo de casca externa. Já o ritidoma rugoso apresenta anéis proeminentes que tornam a superfície acidentada e este é o tipo mais frequentemente encontrado, ocorrendo em Dalbergia frutescens (Vell.) Britton (Figura 5g), Holocalyx balansae Micheli (Figura 7g), Inga marginata Willd. (Figura 8a), Inga striata Benth. (Figura 8h), Lonchocarpus cultratus (Vell.) (Figura 9h), Myroxylon peruiferum L. f. (Figura 12a), Parapiptadenia rigida (Benth.) Brenan (Figura 12f) e Poincianella pluviosa (DC.) L. P. Queiroz (Figura 14a). O ritidoma pode ser ainda áspero, o qual possui fendas profundas e irregulares como observado em Calliandra foliolosa Benth. (Figura 3h) e Cassia leptophylla Vogel. (Figura 4a). Alguns ritidomas podem apresentar placas lenhosas grandes com desprendimento evidente, como observado no tronco maduro de Copaifera langsdorffii Desf. (Figura 4g) ou com depressões ou cicatrizes arredondadas deixadas pelo desprendimento de placas como em Apuleia leiocarpa (Vogel) J.F.Macbr. (Figura 2g). Outros tipos de ritidoma são o laminado, marcado pelo desprendimento de lâminas finas ou o escamoso, que é coberto por placas irregulares de desprendimento, como é o caso de Dahlstedtia muehlbergiana (Hassl.) M.J.Silva \& A.M.G.Azevedo (Figura 5a), Machaerium paraguariense Hassl. (Figura 10g) e Machaerium stipitatum Vogel (Figura 11a).

Os ritidomas sem desprendimento evidente podem ser ainda reticulados, quando o aspecto do tronco é definido por pequenos retículos quadrados aderidos ou fissurados (fendido ou estriado), quando o ritidoma possui sulcos longitudinais rasos ou estrias como é o caso de Bauhinia forficata Link. (Figura 3a) e o tronco jovem de Copaifera langsdorffii Desf. (Figura 4e) ou com sulcos profundos como observado em Erythrina falcata Benth. (Figura 6h), Machaerium nyctitans (Vell.) Benth. (Figura 10a), Mimosa bimucronata (DC.) Kuntze (Figura 11g), Peltophorum dubium (Spreng.) Taub. (Spreng.) Taub. (Figura 13a) e Senegalia recurva (Benth.) Seigler \& Ebinger (Figura 16i).

O ritidoma pode possuir lenticelas que podem ser dispersas, tipo característico em Pterogyne nitens Tul. (Figura 15a), em linhas horizontais como observado em Enterolobium contortisiliquum (Vell.) Morong (Figura 6a) e Schizolobium parahyba (Vell.) S.F. Blake (Figura 15f) e em linhas verticais visto apenas em Leucaena leucocephala (Lam.) R. de Wit. (Figura 9a). Alguns ritidomas apresentam espinhos ou acúleos os como vistos em Gleditsia amorphoides (Griseb.) Taub. (Figura 7a) e Senegalia polyphylla (DC.) Britton \& Rose (Figura 16a), respectivamente.

A coloração avermelhada da casca interna foi encontrada em espécies como Machaerium stipitatum Vogel (Figura 11b), Parapiptadenia rigida (Benth.) Brenan (Figura 12g), Peltophorum dubium (Spreng.) Taub. (Figura13b), Schizolobium parahyba (Vell.) S.F. Blake (Figura 15g) e em caules maduros de Senegalia polyphylla (DC.) Britton \& Rose (Figura 16a), sendo um dos itens citado por Ramos et al. (2008) no guia de identificação para diferenciar as espécies.

O exsudato é um líquido que liberando quando a planta é cortada, frequentemente encontrado nas Leguminosae na forma de goma, a qual é uma substância composta de polissacarídeos, semelhante à resina, porém não possui odor e é solúvel em água (Ribeiro et al. 1999, Carvalho 2003, 2006, Ramos et al. 2008). As espécies Apuleia leiocarpa (Vogel) J.F.Macbr. (Figura 2h), Copaifera langsdorffii 

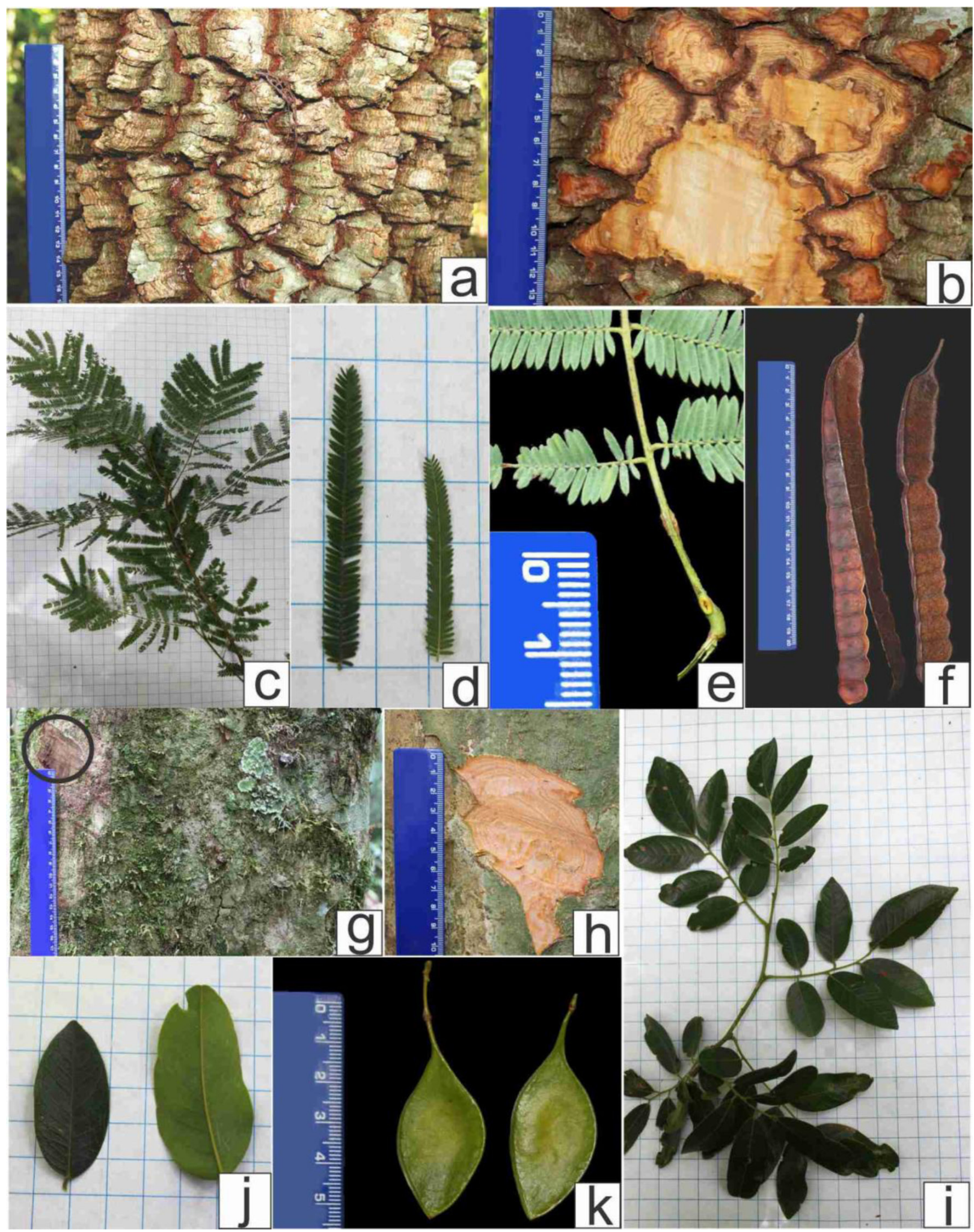

Figura 2. Anadenanthera peregrina var.falcata: a: tronco fortemente cristado com projeções agudas; b: casca interna compacta com coloração laranja-amarelada; c: ramo; d: folíolos face adaxial (esquerda) e face abaxial (direita); e: folha com nectário extrafloral elíptico na base do pecíolo; f: frutos. Apuleia leiocarpa: g: tronco circular, ritidoma com depressões (cicatrizes arredondadas); h: casca interna com anéis laranja-rosado; i: ramo com folíolos variando de oval, elíptico, oblongo a oboval, sendo os apicais maiores que os basais; j: folíolos discolores, face adaxial (esquerda) e face abaxial (direita) com nervura central amarela evidente; k: fruto. Cascavel - PR, 2013.

Figure 2. Anadenanthera peregrine var. falcata: a trunk strongly crested with sharp projections b: yellowish-orange compact inner bark c: branch d: leaflets adaxial (left) and abaxial (right) e: sheet of elliptical extrafloraloral nectaries at the base of the petiole f: fruits. Apuleia leiocarpa: g: circular trunk , rhytidome with depressions (rounded scars) h: inner bark with pinkish orange rings; i: branch with leaflets ranging from oval, elliptical, oblong to oboval, being larger than the apical basal; j: discolor leaflets, adaxial (left) and abaxial (right) with yellow midrib evident, k: fruit.. Cascavel - PR, 2013. 


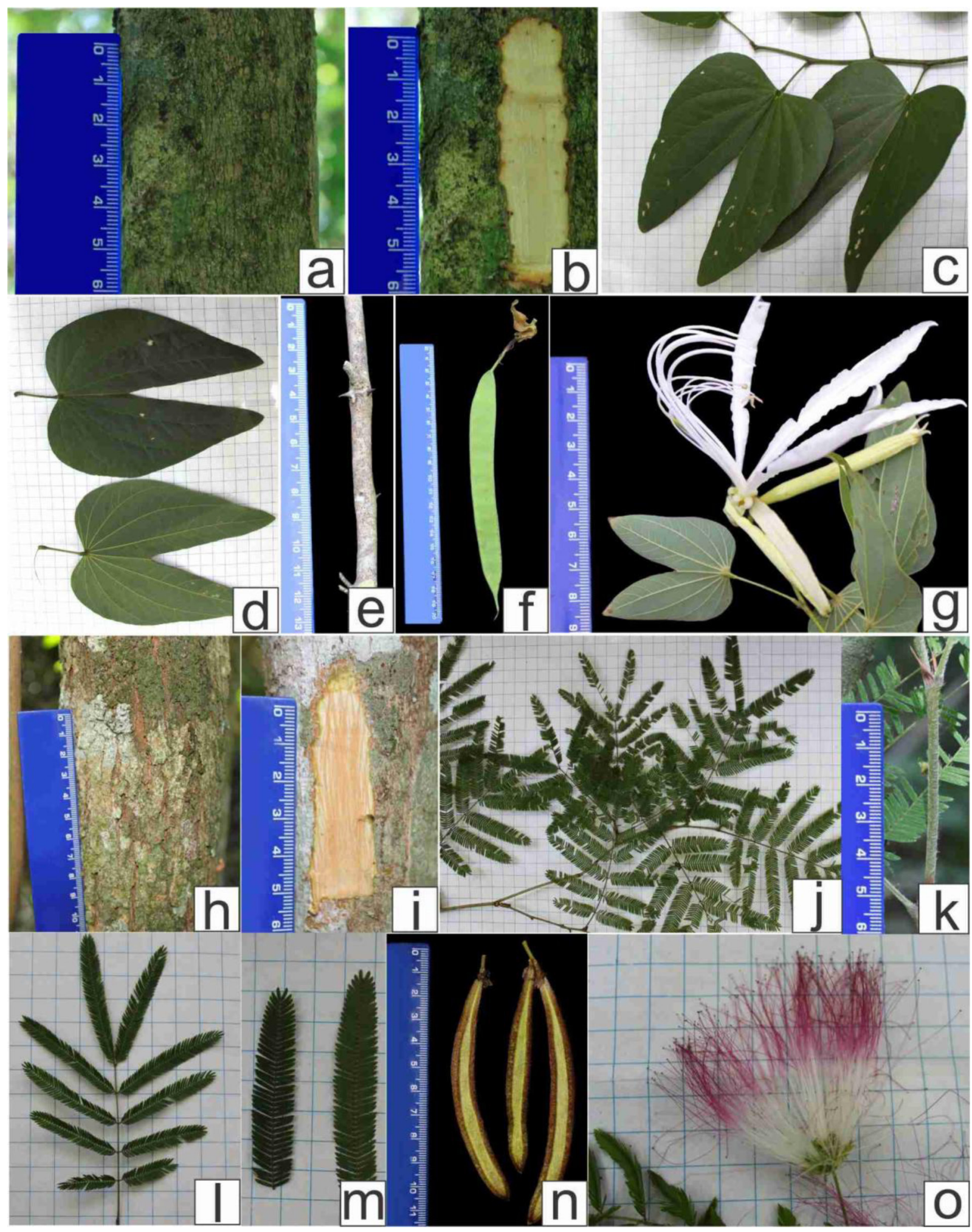

Figura 3. Bauhinia forficata: a: tronco circular, ritidoma com estrias ou sulcos rasos, sem desprendimento evidente; b: casca interna amarela fibrosa; c: parte do ramo; d: folíolos bilobados fundidos até próximo à região mediana da raque, discolores, ápice agudo e base cordata, face adaxial (acima) e face abaxial (abaixo) com nervuras evidentes; e: pares de acúleos na inserção dos ramos; f: fruto; g: ramo com flor. Calliandra foliolosa: h: tronco circular, ritidoma áspero; i: casca interna com fibras de coloração rosa e esbranquiçada; j: ramo; $\mathrm{k}$ : ramo com indumento claro e estípulas foliáceas com indumento castanho; 1: folha bipinada; m: folíolos, face adaxial (esquerda) e abaxial (direita); n: fruto com indumento castanho; o: flor com numerosos estames. Cascavel - PR, 2013.

Figure 3. Bauhinia forficata: a: circular trunk, rhytidome with shallow grooves or striations, without apparent detachment b: yellow fibrous inner bark c: branch part d: fused leaflets bilobed to near the midline of the rachis, discolor, acute apex and base cordata, adaxial (above) and the abaxial (below) with ribs evident, 'and' pair of spines in the insertion of the branches f: product, g: bouquet with flower. Calliandra foliolosa: h: circular trunk, rough rhytidome; i: pink or whitened inner bark fibers $\mathrm{j}$ : branch $\mathrm{k}$ : hairiness branch with clear and stipules foliaceous with brown indument; 1 : bipinada leaf ; m: leaflets, face adaxial (left) and abaxial (right), n: fruit with brown indument, o: flower with numerous stamens. Cascavel - PR, 2013. 


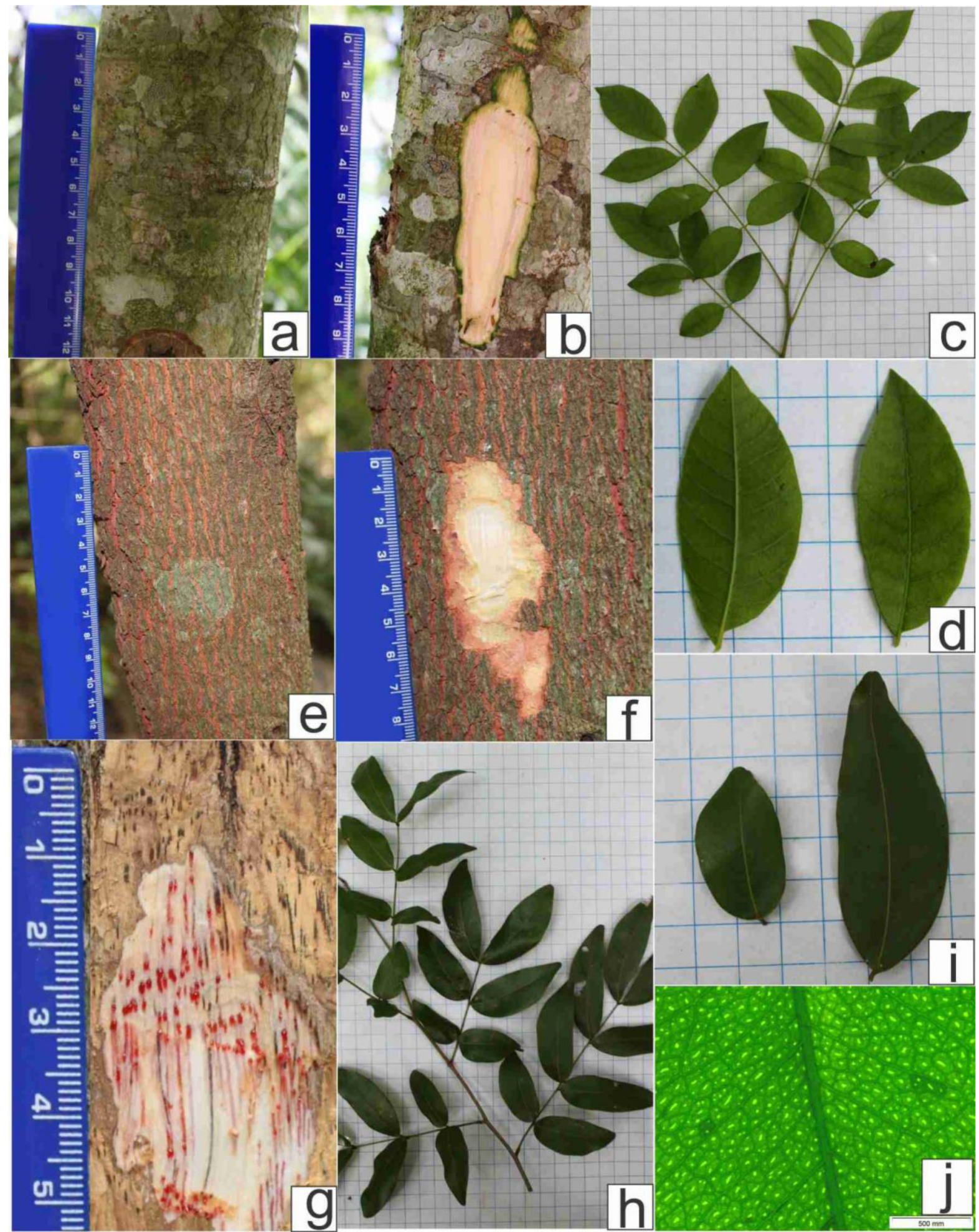

Figura 4. Cassia leptophylla: a: tronco circular, ritidoma áspero; b: casca interna e alburno esbranquiçados; c: ramo com indumento; d: folíolos elípticos concolores, com ápice agudo e base assimétrica, face abaxial (esquerda) com nervura central amarela evidente e face adaxial (direita). Copaifera langsdorffii: e: tronco jovem circular, ritidoma com estrias vermelhas; f: casca interna rosada compacta e alburno esbranquiçado; g: tronco maduro circular, ritidoma com placas lenhosas grandes, casca interna compacta e alburno do indivíduo maduro com exsudato vermelho; h: ramo com folíolos subopostos, apicais maiores que os basais; i: folíolos elípticos a oblongos, ápice arredondado, levemente retuso e base obtusa, face adaxial (esquerda) e face abaxial (direita); j: detalhe das glândulas translúcidas no limbo da folha. Cascavel - PR, 2013.

Figure 4. Cassia leptophylla: a circular trunk, rough rhytidome b: whitened inner bark and sapwood c: branch with hairiness; d: concolores elliptical leaflets , with acute apex and asymmetric base, abaxial (left) with yellow midrib evident and adaxial (right). Copaifera langsdorffi: and: young circular trunk, rhytidome with red streaks f: pink compact inner bark and whitened sapwood g: mature circular trunk, rhytidome with large woody plates, compact inner bark and sapwood of mature guy with red exudate, h: branch; i: sub opposite sheet leaflets, larger apical to the basal j: elliptic to oblong leaflets, apex rounded, slightly retuse and obtuse base, adaxial (left) and abaxial (right); j: detail translucent glands in leaves. Cascavel - PR, 2013 

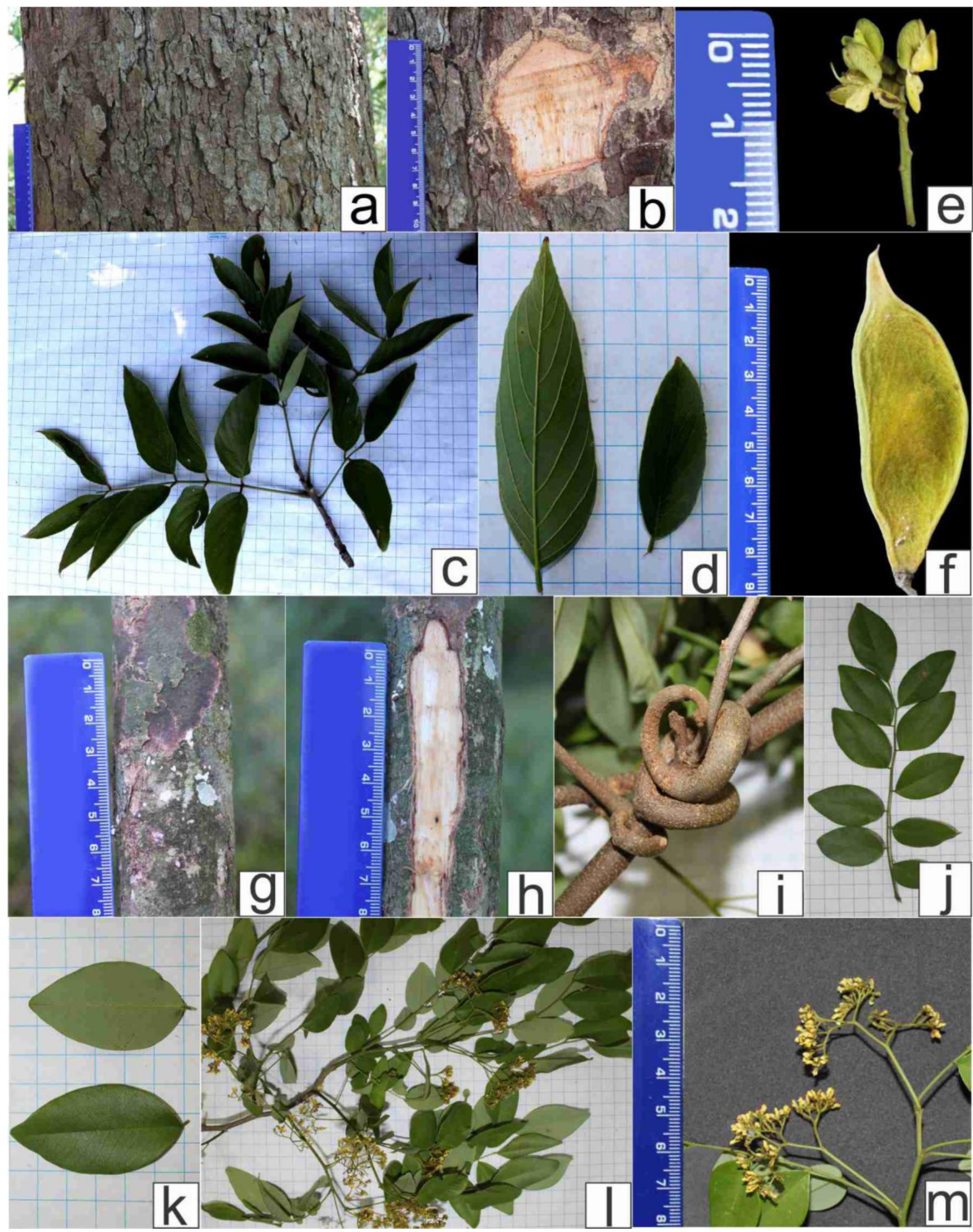

Figura 5. Dahlstedtia muehlbergiana: a: tronco circular, ritidoma escamoso; b: casca interna amarelada; c: ramo; d: folíolos discolores, variando de oval a elíptico, com ápice acuminado e base obtusa a arredondada, face abaxial (esquerda) com nervuras centrais e laterais evidentes e face adaxial (direita); e: flores amareladas; f: fruto com indumento castanho. Dalbergia frutescens: g: tronco reto, com hábito escandente, ritidoma rugoso; h: casca interna esbranquiçada; i: ramo escandente torcido; j: folha; k: folíolos ovais a elípticos, ápice obtuso a acuminado e base obtusos, face adaxial lustrosa (esquerda) e abaxial opaca, puberulenta (direita); 1: ramo com inflorescências; m: inflorescências amarelas. Cascavel - PR, 2013.

Figure 5. Dahlstedtia muehlbergiana : a: circular trunk, scaly rhytidome b: yellowish inner bark; c: branch; d: discolor leaflets , ranging from oval to elliptic, with acuminate apex and obtuse to rounded base, abaxial (left) with central ribs and apparent lateral and adaxial (right); e: yellowish flowers; f: fruit with brown indument. Dalbergia frutescens: g: straight trunk with scandent habit, rough rhytidome h: whitened inner bark; i: scandent twined branch j: leaf; k: ovate to elliptic leaflets, obtuse apex and obtuse to acuminate base, glossy adaxial (left) and opaque abaxial, hairy (right) 1: branch with inflorescences; m: yellow inflorescences. Cascavel - PR, 2013. 

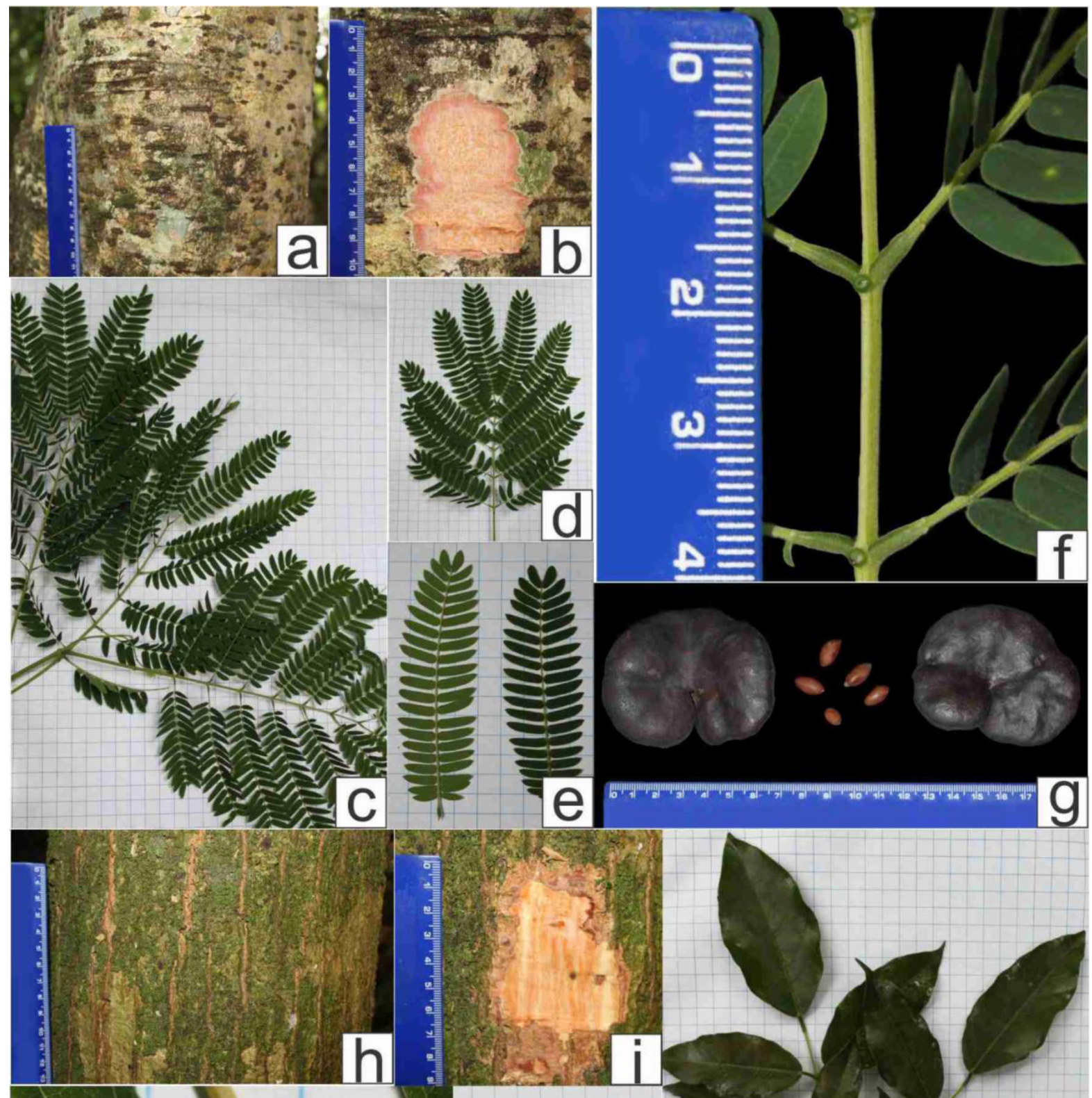


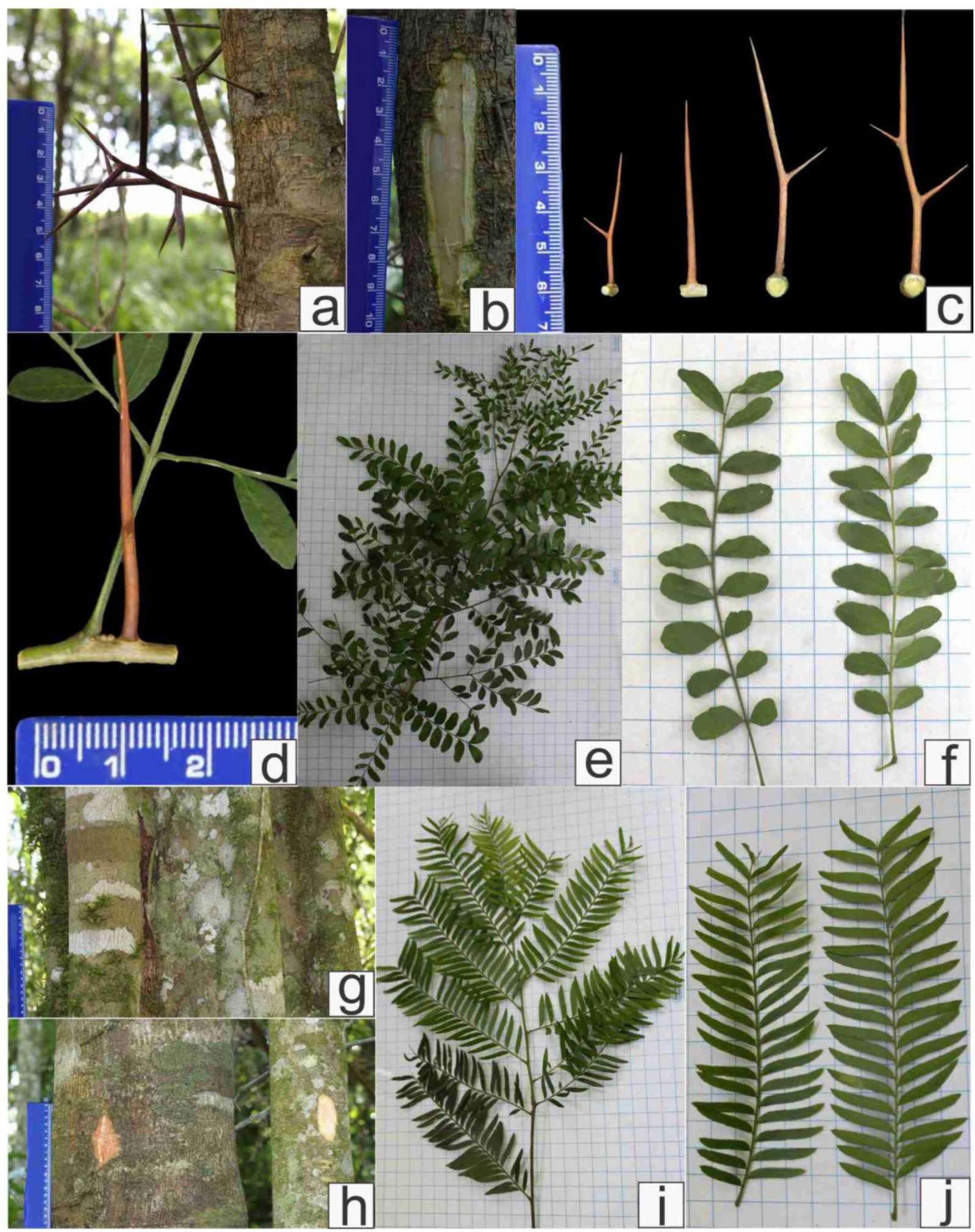

Figura 7. Gleditsia amorphoides: a: tronco circular, ritidoma rugoso com lenticelas e espinhos ramificados; b: casca interna compacta e alburno esbranquiçado; c: espinhos ramificados; d: três gemas acessórias axiais entre a inserção do pecíolo e os acúleos; e: ramo com folhas pinadas e bipinadas; f: folíolos face adaxial (esquerda) e face abaxial (direita) com forma e tamanho irregulares. Holocalyx balansae: g: tronco acanalado, com reentrâncias; h: ritidoma rugoso, casca interna rosada em indivíduo maduro e esbranquiçada em jovens; i: ramo com folhas pinadas, pecíolo com indumento; j: folíolos estreitamente elípticos, base assimétrica, ápice acuminado, face adaxial (esquerda) e abaxial (direita). Cascavel - PR, 2013.

Figure 7. Gleditsia amorphoides: a: circular trunk, rough rhytidome with lenticels and branched spines b: compact inner bark and whitened sapwood c: branched spines d: three ancillary axial Gems between the insertion of the petiole and thorns: and: branch with leaves pinnate and bipinnate; $\mathrm{f}$ : leaflets adaxial (left) and abaxial (right) with irregular shape and size. Holocalyx balansae: g: slotted, recessed trunk h: rough rhytidome, inner bark pinkish in individual mature and whitened in young, i: branch with pinnate leaves, petioles with hairiness; j: narrowly elliptic leaflets, asymmetrical base, acuminate apex, adaxial (left) and abaxial (right). Cascavel - PR, 2013. 


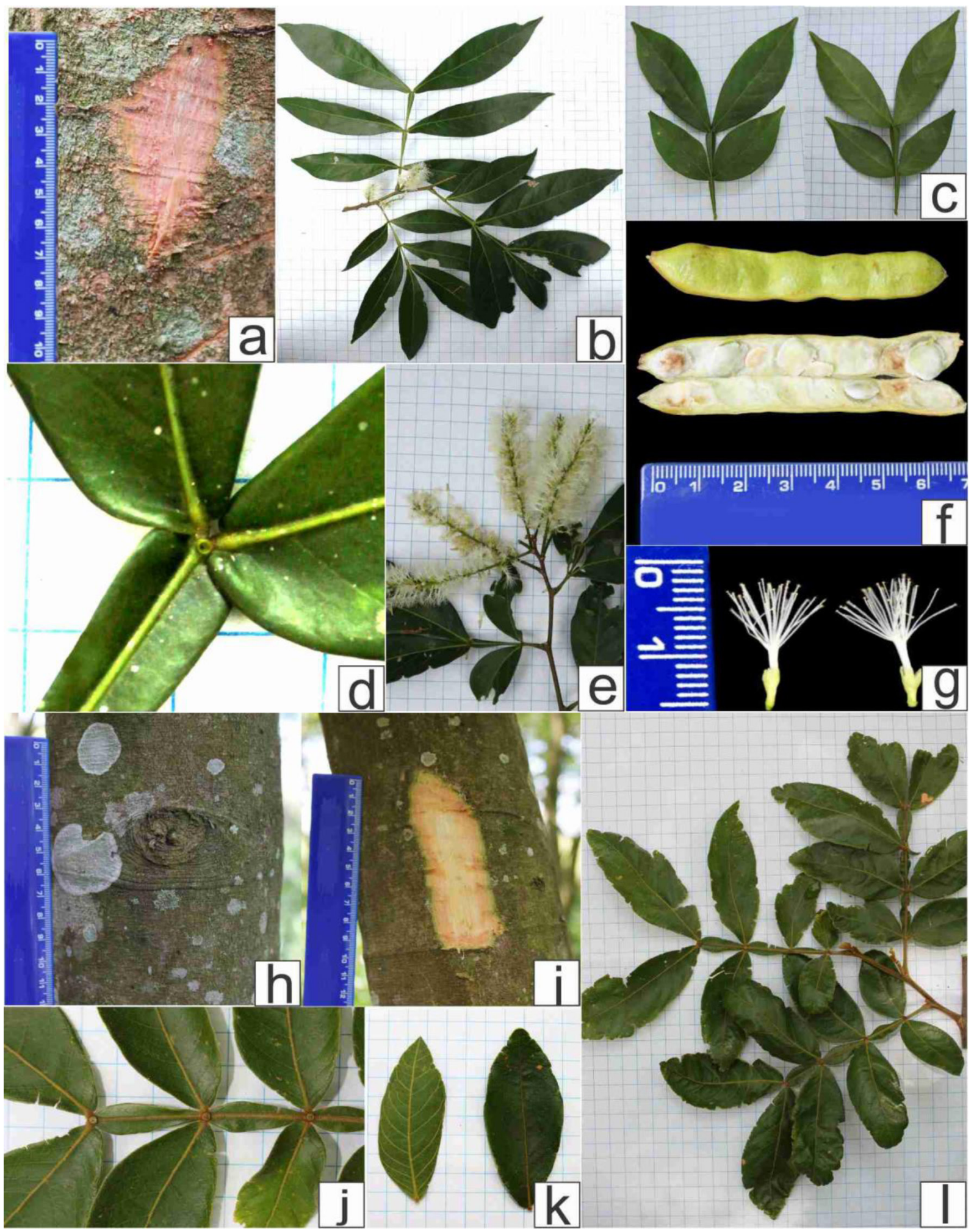

Figura 8. Inga marginata: a: tronco circular, ritidoma rugoso e casca interna rosada; b: ramo com flor; c: folíolos elípticos, ápice acuminado e base aguda, face adaxial (esquerda) e face abaxial (direita); d: raque alada com nectário extrafloral arredondado, entre os pares de folíolos; e: inflorescência; f: frutos; g flores. Inga striata: h: tronco cilíndrico, ritidoma rugoso; i: casca interna compacta amarela-rosada; j: indumento castanho na raque alada e nas nervuras, uma nectário extrafloral arredondado entre cada par de folíolos; k: folíolos discolores, elíptico-ovado, ápice agudo e base obtusa, face abaxial (esquerda) mais clara com nervura evidente e face adaxial (direita); 1: ramo. Cascavel - PR, 2013.

Figure 8. Inga marginata: a: circular trunk, rough rhytidome and pinkish inner bark b: branch with flower c: elliptic leaflets, acuminate apex and acute base, adaxial (left) and abaxial (right) d: winged rachis with rounded extrafloral nectary, between pairs of leaflets, and e: inflorescence f: fruits, flowers g. Inga striata: h: cylindrical trunk, rough rhytidome, i: pinkish-yellow compact inner bark j: brown indument on the winged rachis and the ribs, extrafloral nectary between each pair of rounded leaflets; $\mathrm{k}$ : discolor leaflets, elliptic-ovate, acute apex and obtuse base, abaxial (left) with lighter midrib evident and adaxial (right), 1: branch. Cascavel - PR, 2013. 

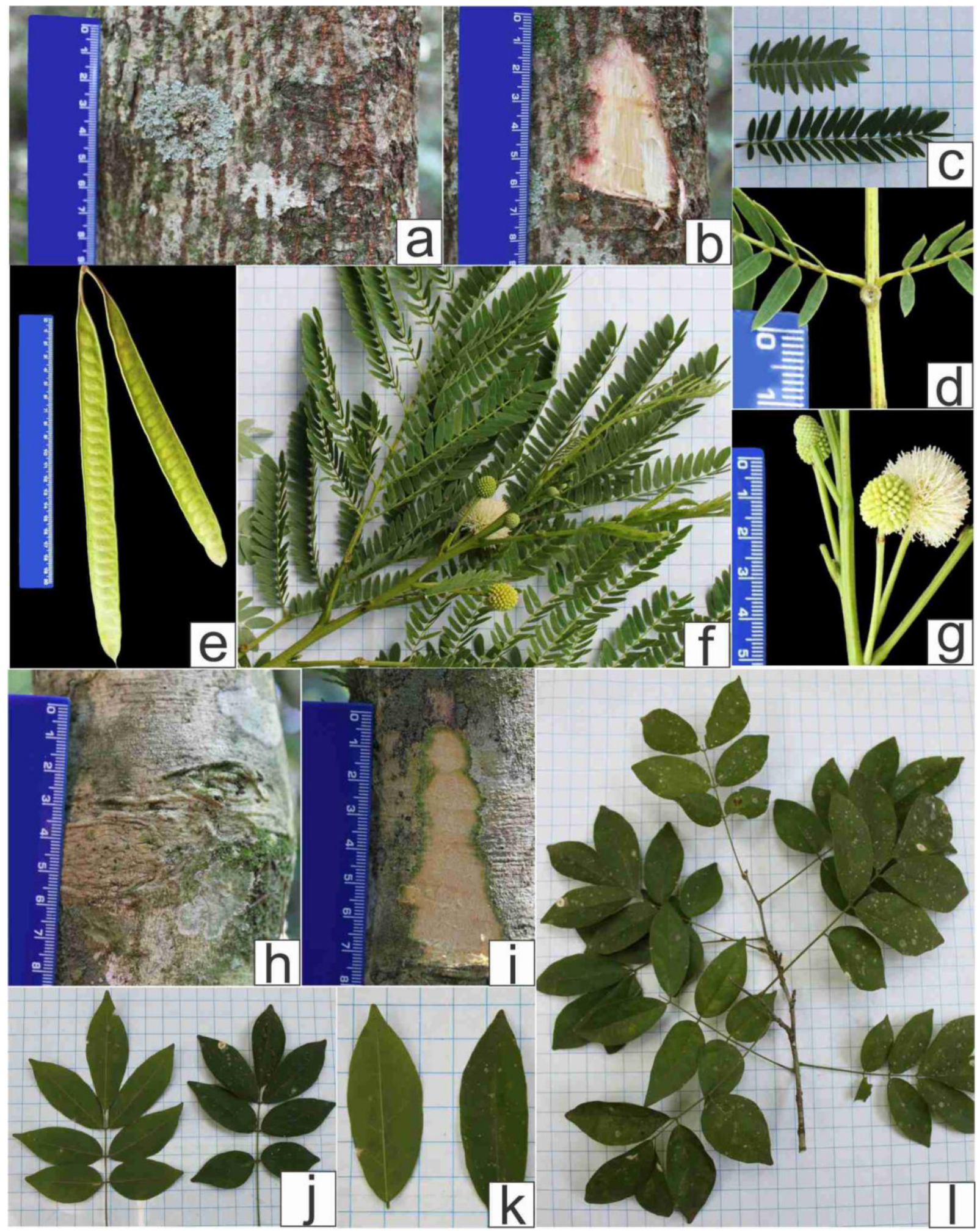

Figura 9. Leucaena leucocephala: a: tronco circular, ritidoma com lenticelas em linhas verticais; b: casca interna rosada e alburno fibroso amarelado; c: folíolos discolores, com variação de tamanho, face abaxial (esquerda) e face adaxial (direita); d: nectário extrafloral grande e arredondado na porção apical do pecíolo; e: frutos; f: ramo fértil com flor; g: flor e botões. Lonchocarpus cultratus: h: tronco circular, ritidoma rugoso; i: casca interna amarelada; j: folhas pinadas, face abaxial (esquerda) e adaxial (direita), folíolos apicais elípticos e folíolos basais ovais; k: folíolos com ápice acuminado e discolores, face abaxial tomentosa (esquerda) com nervura central amarela evidente e face adaxial (direita).; 1: ramo. Cascavel - PR, 2013.

Figure 9. Leucaena leucocephala: a: circular trunk, rhytidome with lenticels in vertical lines, b: pinkish inner bark and yellowish fibrous sapwood c: bipinnate compound sheet d: discolor leaflets, varying in size, abaxial (left) and adaxial (right) and: large and rounded extrafloral nectary in the apical portion of the petiole f: fruits; g: branch with fertile flowers; h: flower and buttons. Lonchocarpus cultratus: circular trunk, rough rhytidome b: yellowish inner bark c: branch d: pinnate leaves, the abaxial (left) and adaxial (right), apical leaflets elliptical and basal leaflets oval, and: leaflets with acuminate and discolor apex, face abaxial tomentosa (left) with yellow midrib evident and adaxial (right). Cascavel - PR, 2013. 

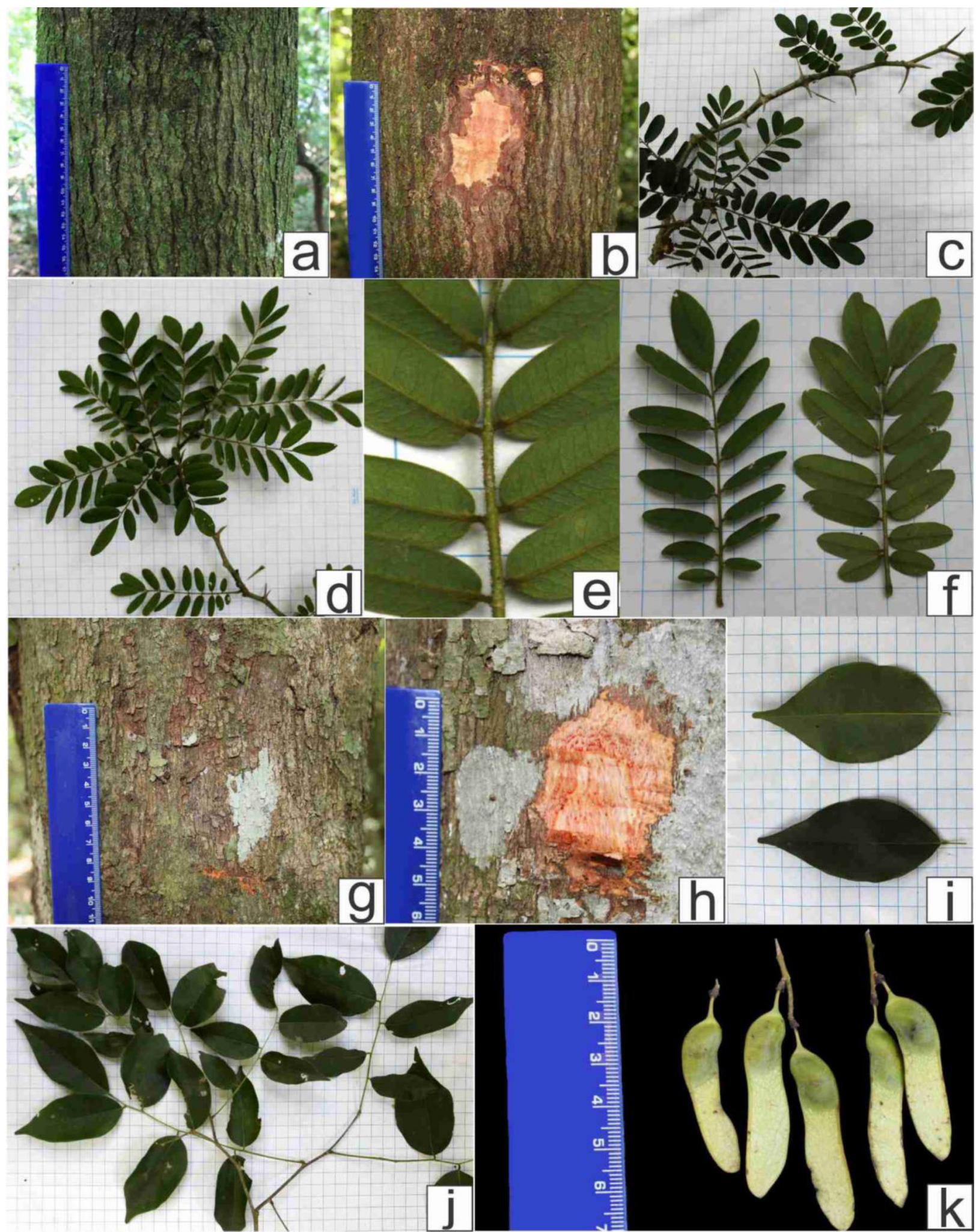

Figura 10. Machaerium nyctitans: a: tronco circular, ritidoma com sulcos profundos sem desprendimento evidente; b: casca interna compacta rosa-amarelada; c: ramo com espinhos longos aos pares; d: ramo com folhas; e: indumento castanho na raque e nas nervuras; f: folhas compostas, com folíolos geralmente oblongos, ápice e base arredondados, face adaxial (esquerda) e face abaxial com indumento (direita). Machaerium paraguariense: g: tronco circular, ritidoma escamoso; h: casca interna rosa com exsudato vermelho; i: folíolos ovais, ápice acuminado e base arredondada, face abaxial (acima) com nervura central amarela evidente e face adaxial (abaixo); j: ramo; k: frutos. Cascavel - PR, 2013.

Figure 10. Machaerium nyctitans: circular trunk, rhytidome with deep grooves without apparent detachment; b: yellowish-pink compact inner bark c: branch with long thorns in pairs; $\mathrm{d}$ : branch with leaves; e: brown indument on the rachis and the ribs f: compound leaves with leaflets usually oblong, apex and base rounded, adaxial (left) and abaxial surface with indument (right). Machaerium paraguariense: g: circular trunk, scaly rhytidome; h: pinkinner bark with red exudate; i: ovate leaflets, acuminate apex and rounded base, abaxial (above) with yellow midrib evident and adaxial (below); j: branch k: fruits. Cascavel - PR, 2013. 


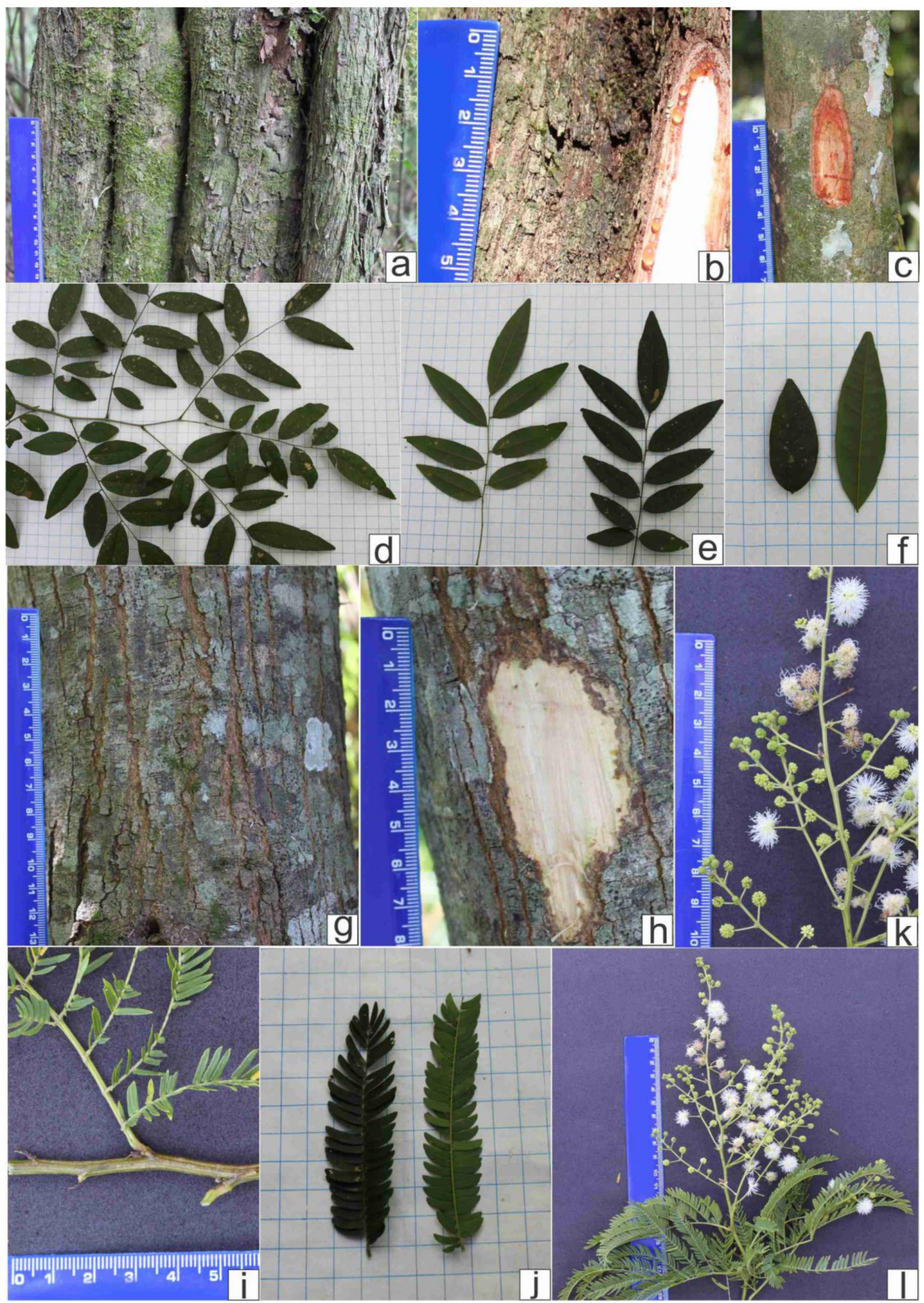

Figura 11. Machaerium stipitatum: a: tronco acanalado, ritidoma escamoso; b: casca interna marrom com exsudato vermelho e alburno branco; c: tronco circular de indivíduo jovem com casca interna vermelha e exsudato vermelho; d: ramo; e: folhas pinadas, face abaxial (esquerda) e face adaxial (direita), folíolos elípticos (apicais) a ovais (basais), ápice agudo a emarginado e base obtusa a aguda; f: folíolos levemente discolor, face adaxial (esquerda) e face abaxial (direita). Mimosa bimucronata: g: ritidoma com sulcos profundos, sem desprendimento evidente e com acúleos; h: casa interna esbranquiçada e fibrosa; i: ramo com estípula; j: folíolos levemente discolores, face adaxial (esquerda) e face abaxial (direita); k: detalhes das inflorescências cimosas; 1: ramo fértil com flor alva. Cascavel - PR, 2013

Figure 11. Machaerium stipitatum: a: slotted stem, squamous rhytidome b: brown inner bark with red exudate and white sapwood c: young circular trunk with red inner bark and red exudate d: branch: and, pinnate leaves, the abaxial (left) and adaxial (right), elliptical leaflets (apical) to oval (baseline), acute to emarginate apex and base obtuse to acute; f: leaflets slightly discolor, adaxial (left) and abaxial (right). Mimosa bimucronata: g: rhytidome with deep grooves without apparent detachment and prickles; h: withish fibrous internal house; i: branch with stipules; j: leaflets slightly discolor, adaxial (left) and abaxial (right) k: details of inflorescences flufy; 1: fertile branch with alb flower . Cascavel - PR, 2013. 


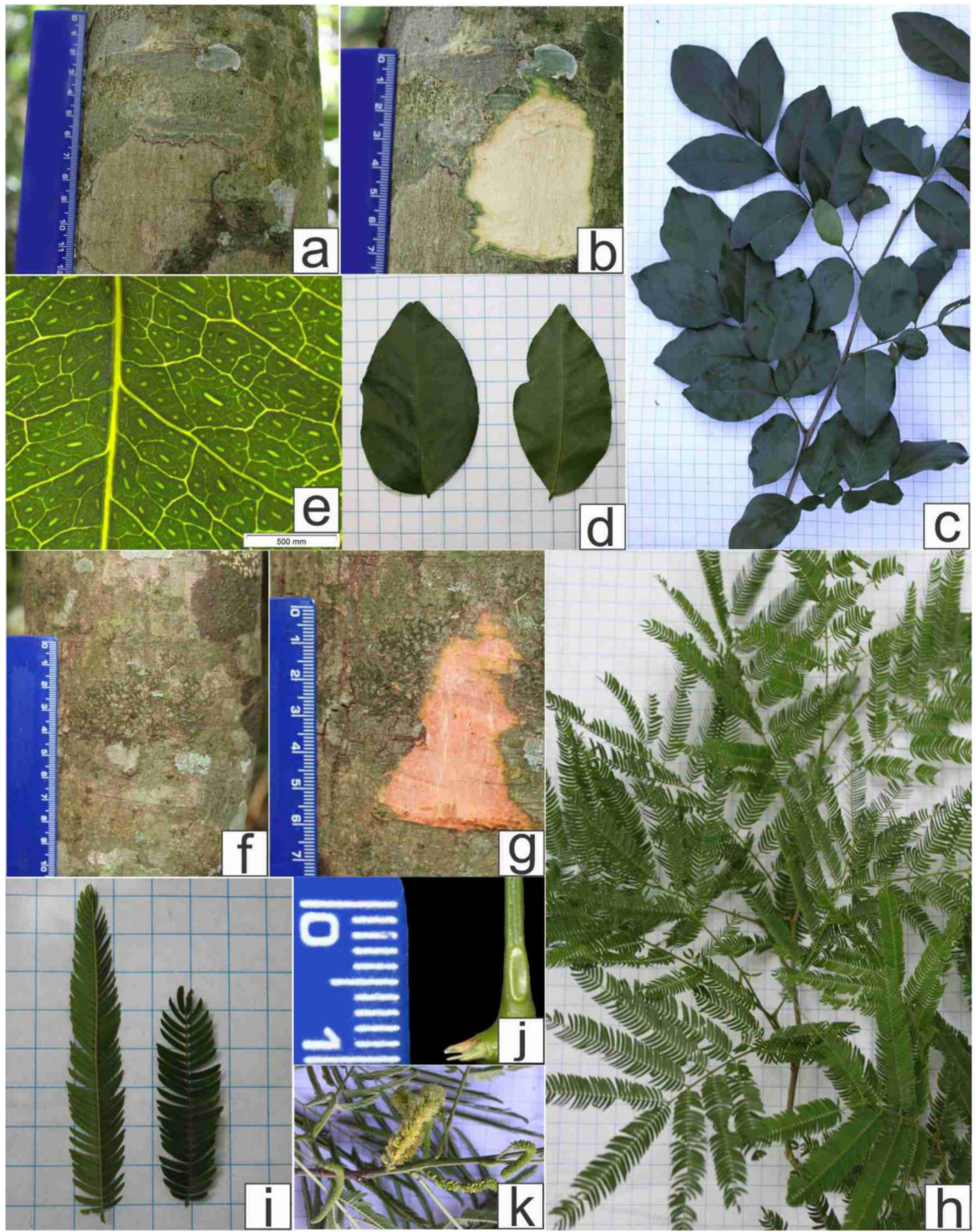

Figura 12. Myroxylon peruiferum: a: tronco circular, ritidoma rugoso; b: casca interna compacta branca; c: ramo folhas imparipinadas; d: folíolos elípticos a ovais, ápice emarginado e base arredondada, face adaxial (esquerda) e face abaxial (direita) com nervura central amarela evidente; e: detalhe das glândulas translúcidas em forma de traços no limbo. Parapiptadenia rigida: f; tronco circular, ritidoma rugoso, desprendendo-se em placas em indivíduos maduros; g: casca interna compacta rosada; h: ramo; i: folíolos, face abaxial (esquerda) e face adaxial (direita); j: nectário extrafloral na base do pecíolo; k: ramo com inflorescência em espiga. Cascavel - PR, 2013.

Figure 12. Myroxylon peruiferum: a: circular trunk, rough rhytidome b: white compact inner bark c: branch with imparipinnate leaves d: ovate to elliptic leaflets, emarginated apex and rounded base, adaxial (left) and abaxial (right) with yellow central rib evident, e: detail of traced-shaped translucent glands in limbo. Parapiptadenia rigida: f; circular trunk, rough rhytidome, loosening up on plates in mature individuals; g: pinkish compact inner bark, h: branch; i: leaflets, abaxial (left) and adaxial (right); j: extrafloral nectary at the base of the petiole; k: branch with spike inflorescence. Cascavel - PR, 2013. 

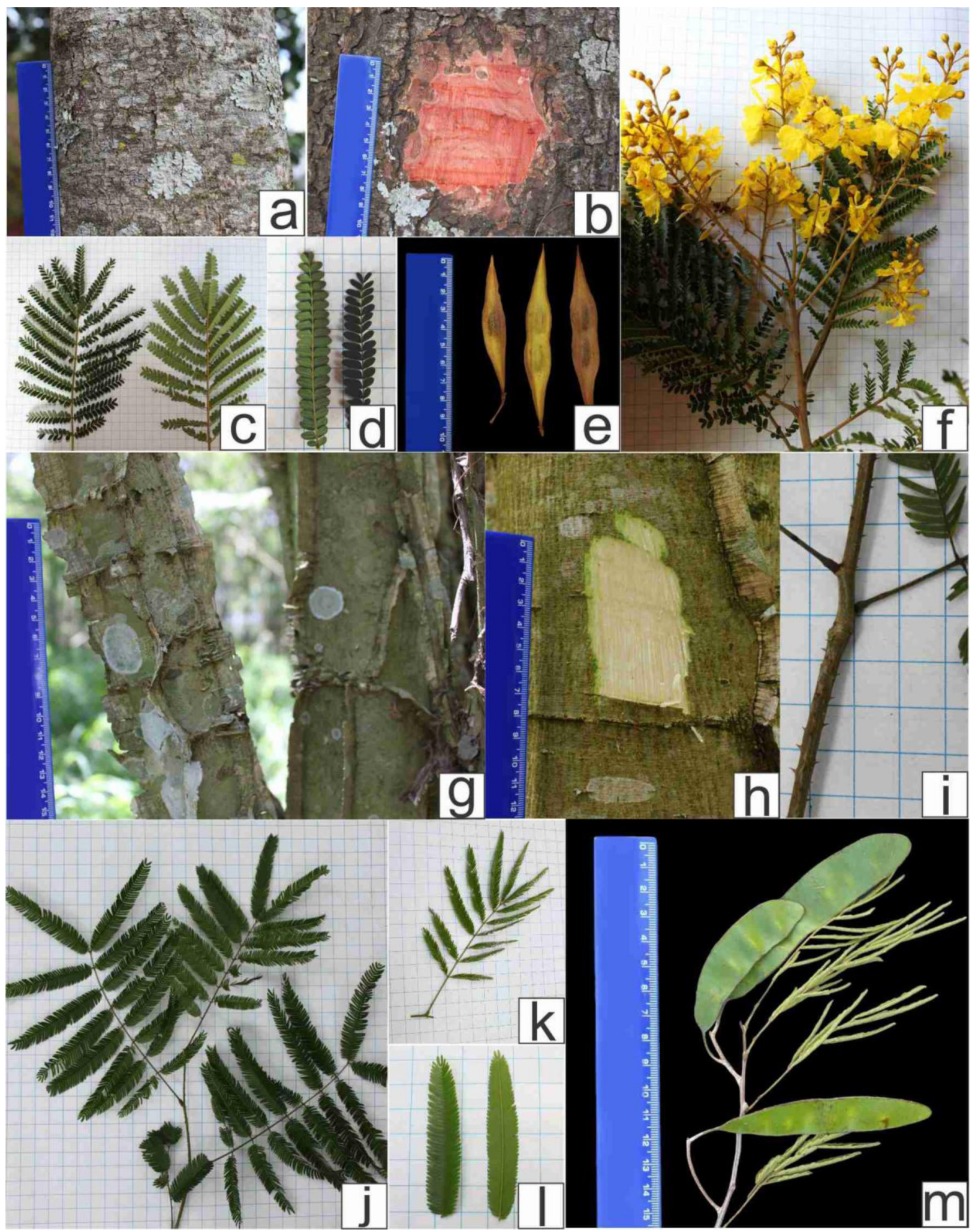

Figura 13. Peltophorum dubium: a: tronco circular, ritidoma com sulcos profundos sem desprendimento evidente; b: casca interna rosa a avermelhada; c: folhas bipinadas, face adaxial (esquerda) e face abaxial (direita); d: folíolos, face abaxial (esquerda) e face adaxial (direita); e: frutos com uma a duas sementes; f: ramo com indumento castanha, com estípula foliácea e flor amarela. Piptadenia gonoacantha: g: tronco cristado, ritidoma com lâminas perpendiculares ; h: casca interna esbranquiçada; i: ramo com acúleos; j: ramo com folhas; $\mathrm{k}$ : folha bipinada; 1: folíolos face adaxial (esquerda) e face abaxial (direita); m: ramo fértil com frutos imaturos. Cascavel - PR, 2013.

Figure 13. Peltophorum dubium: a: circular trunk, rhytidome with deep grooves without apparent detachment b: pink to reddish inner bark c: bipinnate leaves, adaxial (left) and abaxial (right) d: leaflets, abaxial (left) and adaxial (right ) and: fruits with one to two seeds f: branch with brown indument, with stipules foliated and yellow flower. Piptadenia gonoacantha: g: crested trunk, rhytidome with perpendicular blades, h: whitened inner bark; i: branch with thorns; j: branch with leaves; k: bipinnate leaf, 1: leaflets adaxial (left) and abaxial (right); $\mathrm{m}$ : fertile branch with unripe fruit. Cascavel - PR, 2013. 

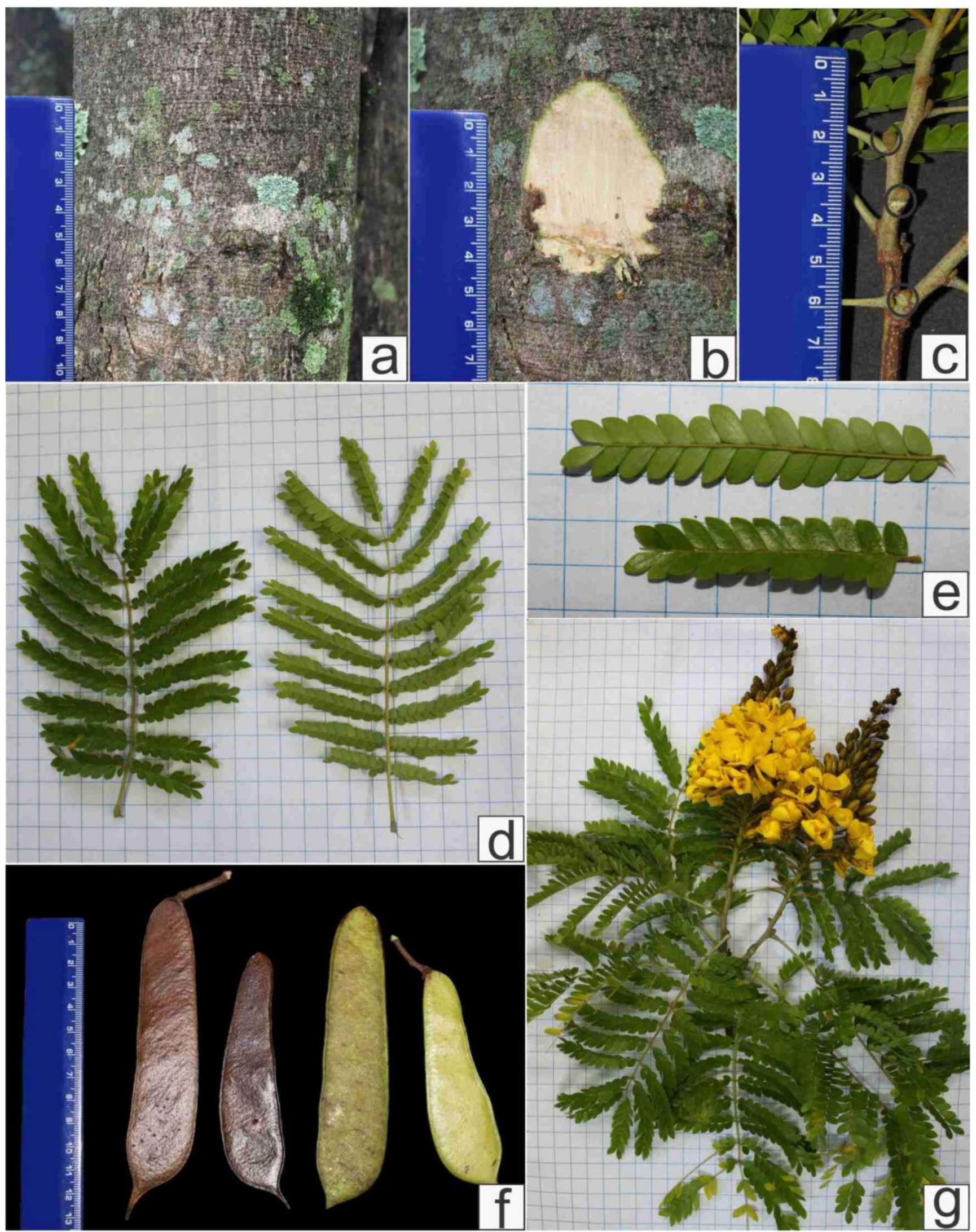

Figura 14. Poincianella pluviosa: a: tronco circular, ritidoma rugoso; b: casca interna compacta esbranquiçada; c: gema globosas, com indumento castanha; d: folhas face adaxial (esquerda) e face abaxial (direita); e: folíolos, face abaxial (acima) e face adaxial (abaixo); f: frutos; g: ramo fértil com inflorescência e flores amarelas. Cascavel - PR, 2013.

Figure 14. Poincianella pluviosa: circular trunk, rough rhytidome b: whitened compact inner bark c: globule yolk, with brown indument; d: leaf adaxial (left) and abaxial (right) and: leaflets, abaxial surface (above) and adaxial (below) f: fruits; g: fertile branch with inflorescence and yellow flowers. Cascavel - PR, 2013. 

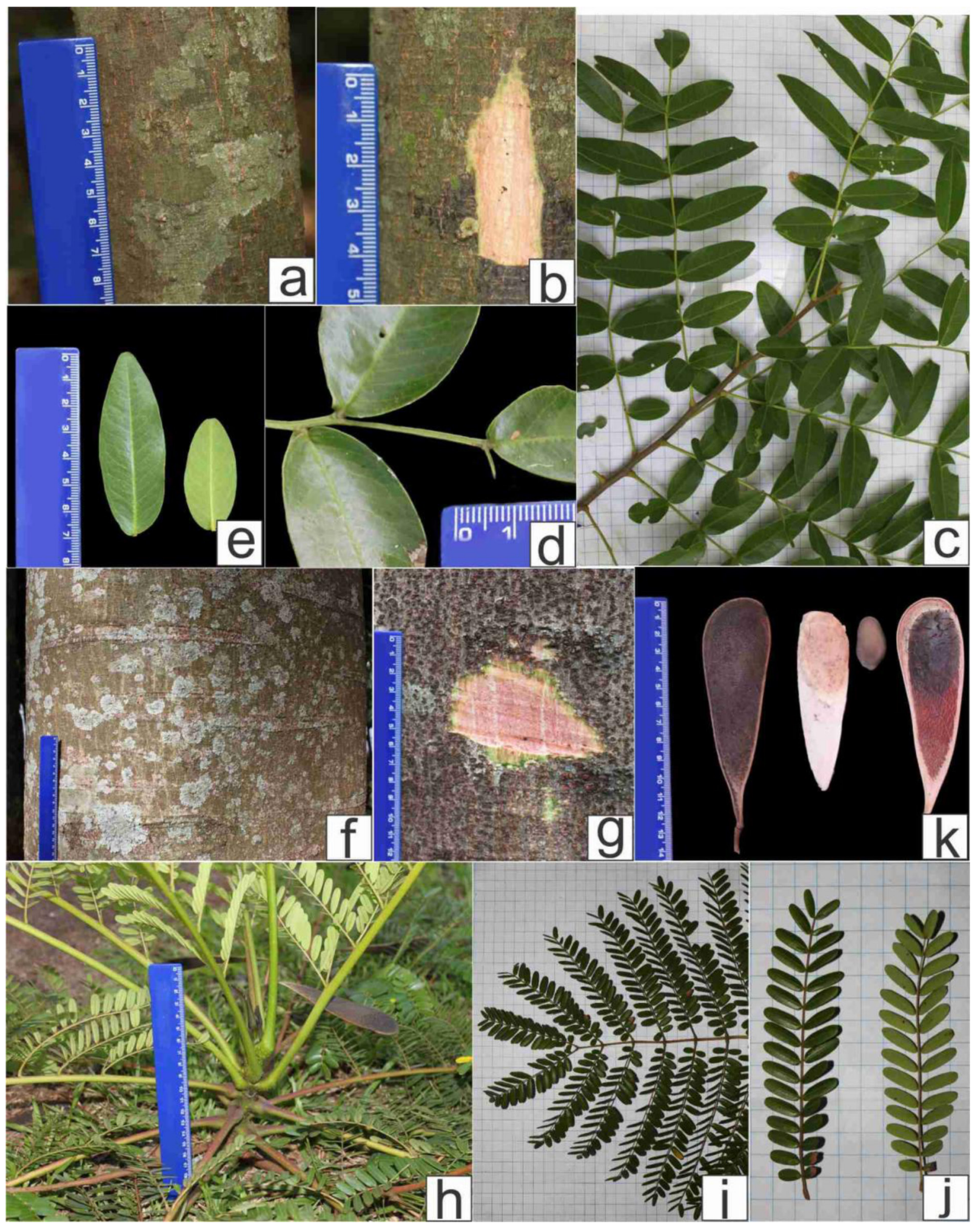

Figura 15. Pterogyne nitens: a: tronco circular, ritidoma com lenticelas dispersas; b: casca interna com estrias rosa-esbranquiçadas; c: ramo; d: folhas compostas terminando em apêndice; e: folíolos elípticos a oblongos, ápice arredondado e base obtusa, face adaxial (esquerda) e face abaxial (direita) com nervura central evidente. Schizolobium parahyba: f: tronco circular, ritidoma com lenticelas, cicatrizes horizontais da inserção das folhas; g: casca interna rosada e estriada; h: ramo com folhas bipinadas, ramos jovens clorofilados, indumento viscosa nos ramos e foliólulos; i: parte da folha; j: folíolos, face adaxial (esquerda) e face abaxial (direita); k: fruto, endocarpo que envolve a semente, semente e parte interna do fruto. Cascavel - PR, 2013.

Figure 15. Pterogyne nitens: a: circular trunk, rhytidome with scattered lenticels b: inner bark with pink white streaked c: branch d: compound leaves ending in Appendix: and, elliptic to oblong leaflets, rounded apex, obtuse base, adaxial (left) and abaxial (right) with midrib evident. Schizolobium parahyba: f: circular trunk, rough rhytidome with lenticels, horizontal scars of outer leaves; g: pinkish striated inner bark; h: branch with bipinnate leaves, young branches chlorophyllous, stems and viscous hairiness leaflets; i: part of the sheet; $\mathrm{j}$ : adaxial (left) and abaxial (right) leaflets k: fruit, cored around the seed, seed and fruit internal part.Cascavel - PR, 2013. 

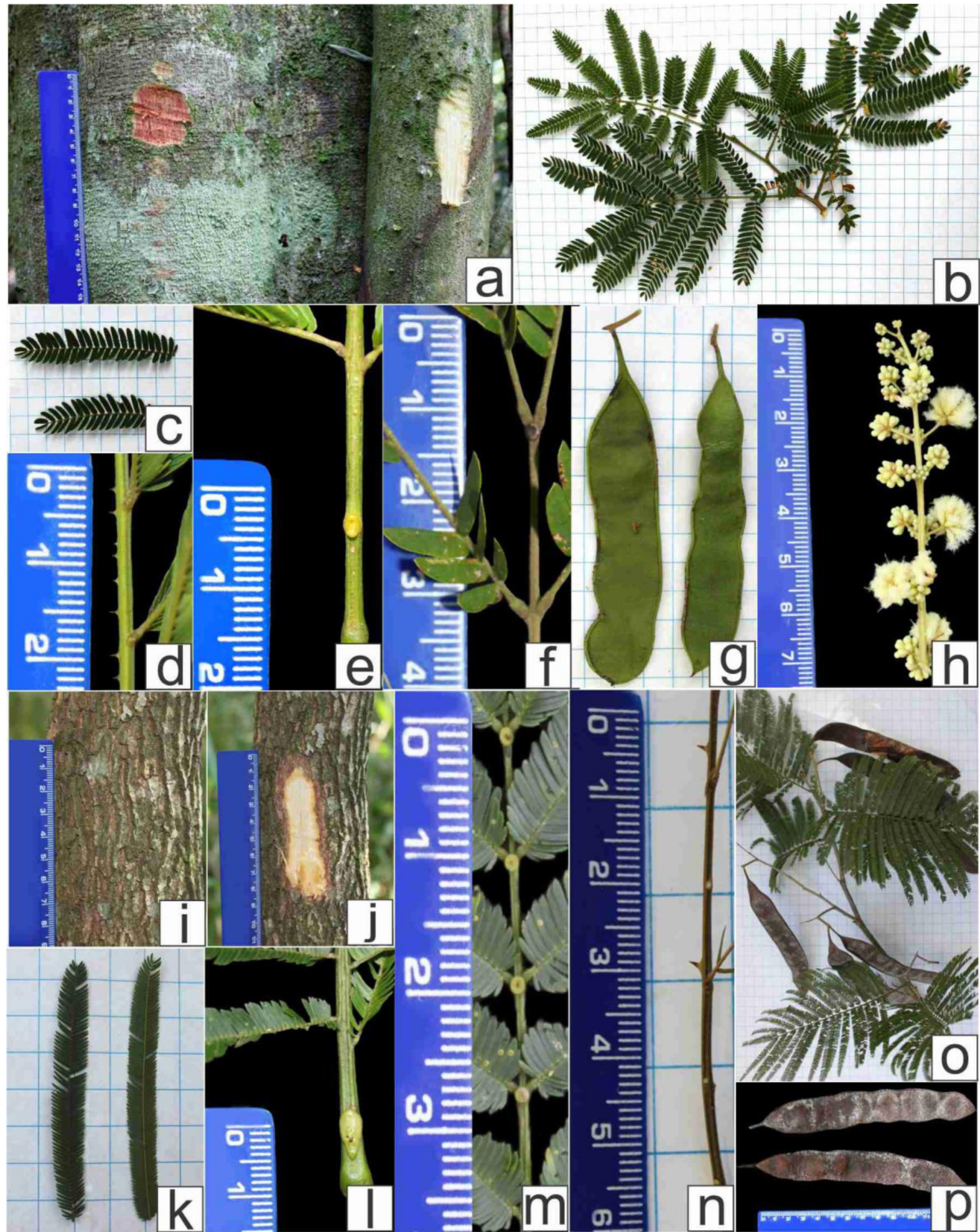

Figura 16. Senegalia polyphylla: a: caule circular, ritidoma com acúleos, casca interna vermelha em indivíduos maduros e esbranquiçada em jovem; b: ramo com folhas bipinadas com indumento; c: folíolos, face adaxial (abaixo) e face abaxial (acima) d: detalhe dos acúleos na raque; e: nectário extrafloral circular a oval na base do pecíolo; f: nectário extrafloral arredondado entre os pares de folíolos apicais; g: frutos; h: inflorescência cimosa. Senegalia recurva: i: tronco circular, ritidoma com sulcos profundos e sem desprendimento evidente; j: casca interna compacta e esbranquiçada; k: folíolos, face adaxial (esquerda) e abaxial (direita); 1: nectário extrafloral alongado no pecíolo m: nectário extrafloral arredondado entre os 4 pares de folíolos apicais; n: espinhos na raque; o: ramo com frutos; p: frutos. Cascavel - PR, 2013.

Figure 16. Senegalia polyphylla: a: circular stem, rhytidome with spines, red inner bark in mature individuals and whitened in young b: branch with leaves bipinnate with indumental, c: leaflets, adaxial (below) and abaxial (above) d: detail of spines on the rachis, and: circular to oval extrafloral nectary at the base of the petiole f: rounded extrafloral nectary between pairs of leaflets apical g: fruit, h: cimosa inflorescence. Senegalia recurva: i: circular trunk with deep grooves and no obvious detachment $\mathrm{j}$ : whitened compact inner bark k: leaflets, adaxial (left) and abaxial (right), 1: petiole elongated extrafloral nectary m: extrafloral nectary between the rounded 4 pairs of leaflets apical, n: thorns in the rachis, o: branch with berries, p: fruit.Cascavel - PR, 2013. 
Desf. (Figura 4g), Machaerium paraguariense Hassl. (Figura 10h), Machaerium stipitatum Vogel (Figura 11b) e Schizolobium parahyba (Vell.) S.F. Blake (Figura 15g) apresentaram exsudato característico, que pode auxiliar nas identificações destas espécies em campo. Esta substância extraída dos caules pode ser utilizada para variados fins, como exemplo podemos citar o óleo-de-copaíba, extraído da espécie Copaifera langsdorffii que tem propriedades medicinais e aplicação comercial, segundo vários estudos já realizados (Pieri et al. 2009, Montes et al. 2009, Yamaguchi \& Garcia 2012).

As glândulas são estruturas com variadas formas e funções (Cardoso 2011). No presente estudo foram avaliadas, basicamente, dois tipos de glândulas. As primeiras são glândulas translúcidas imersas no limbo, observadas em Copaifera langsdorffii Desf. (Figura 4j) e Myroxylon peruiferum L. f. (Figura 12e), que podem ser notadas, através de uma fonte de luz ascendente, característica também observada por Ramos et al. (2008), Filardi et al. (2009), Eltink et al. (2011), Iglesias et al. (2011) na espécie Copaifera langsdorffii Desf. O segundo tipo de glândula observada foram os nectários extraflorais, quando produtoras de açúcar, característica comprovada por Melo et al. (2010) e Cardoso (2011) que podem estar presentes nos pecíolos, como é o caso em Anadenanthera peregrina var. falcata (Benth.) Altschul. (Figura 2e), Parapiptadenia rigida (Benth.) Brenan (Figura 12j) e Piptadenia gonoacantha (Mart.) J.F.Macbr (Figura 13k). As espécies Senegalia polyphylla (DC.) Britton \& Rose (Figura 16e) e Senegalia recurva (Benth.) Seigler \& Ebinger (Figura 161) apresentam nectários extraflorais axiais, já em Gleditsia amorphoides (Griseb.) Taub. (Figura 7d) são encontrados na região de inserção das folhas ou na raque e em Enterolobium contortisiliquum (Vell.) Morong (Figura 6f), Erythrina falcata Benth. (Figura 6j), Inga marginata Willd. (Figura 8d) e Inga striata Benth. (Figura 8j) os nectários extraflorais localizam-se entre os pares de folíolos. Os nectários extraflorais estão presentes em várias espécies da família Leguminosae como observado por Urbanetz et al. (2010). Destaca-se Erythrina falcata Benth. (Figura 6j) que possui um par de nectários extraflorais entre os folíolos, que facilitam a identificação desta espécie.

Espinhos ou acúleos são de fácil visualização e tem grande importância na identificação vegetativa. Encontrou-se uma variação no formato, quantidade e localização destes nas diferentes espécies. Em Gleditsia amorphoides (Griseb.) Taub. (Figura 7a, c) ocorrem espinhos ramificados no tronco e nos ramos, em Machaerium nyctitans (Vell.) Benth. (Figura 10c) espinhos longos, em pares nos ramos. Já em Bauhinia forficata Link. (Figura 3e) ocorre um par de acúleos localizados abaixo da inserção de cada ramo. As demais espécies armadas encontradas possuem acúleos isolados ao longo do caule e/ou ramos como em Erythrina falcata Benth. (Figura 61), Mimosa bimucronata (DC.) Kuntze e Piptadenia gonoacantha (Mart.) J.F.Macbr. (Figura 13g, i), sendo que em Senegalia polyphylla (DC.) Britton \& Rose (Figura 16 d) e Senegalia recurva (Benth.) Seigler \& Ebinger (Figura 16n) ocorrem acúleos também na raque.

Estípulas são folhas modificadas, frequentemente em pares, na base das folhas e são geralmente caducas (Gonçalves \& Lorenzi 2011). Estas estruturas foram visualizadas em Mimosa bimucronata (DC.) Kuntze (Figura 11i), onde são falciformes, glabras com coloração escura, em Calliandra foliolosa Benth. (Figura 3k), visíveis, com indumento e coloração castanha e em Peltophorum dubium (Spreng.) Taub. (Spreng.) Taub. a qual é foliácea.

Indumento é o conjunto de tricomas (Gonçalves \& Lorenzi 2011) que pode ser percebido a olho nu ou com o auxilio de lupa, e embora a quantidade seja bastante variável, a presença ou ausência de indumento foi importante para a distinção das espécies do gênero Inga. A espécie Inga marginata Willd. (Figura 8c, d) apresentou folíolos glabros e em Inga striata Benth. (Figura 8j, k) os folíolos apresentaram indumento castanho nas folhas, principalmente ao longo das nervuras.
Desta forma, características do tronco, ritidoma, coloração da casca interna, presença de exsudato, acúleos, características das folhas como formato dos folíolos e presença de glândulas ou de nectários extra-florais foram de grande valia em campo, permitindo a identificação das espécies de Leguminosae nos fragmentos de Floresta Estacional Semidecidual do Corredor de Biodiversidade de Santa Maria, no sudoeste do Paraná.

\section{Agradecimentos}

À Coordenação de Aperfeiçoamento de Pessoal de Nível Superior (Capes) pela bolsa cedida ao primeiro autor, às especialistas Cristiane Snak e Roseli Lopes da Costa Bortoluzzi pelas identificações, bibliografias cedidas e leitura do manuscrito. Às agências de fomento FAPESP (processo $n^{\circ} 2010 / 17400-3$ ), CNPq (processo $n^{\circ}$ 562240/2010-1) e Fundação Araucária (processo no 15694 -13/2009) pelo auxílio financeiro durante a execução deste trabalho.

\section{Referências Bibliográficas}

ASH, A., ELLIS, B., HICKEY, L.J., JOHNSON, K., WILF, P. \& WING, S. 1999. Manual of leaf Architecture - morphological description and categorization of dicotyledonous and net-veined monocotyledonous angiosperms by Leaf Architecture Working Group. Smithsonian Institution, Washington.

BARNEBY, R.C. 1991. Sensitivae censitae: a description of the genus Mimosa Linnaeus (Mimosaceae) in the New World. Mem. New York Bot. Gard. 65:1-835.

BRASIL. Ministério do Meio Ambiente-MMA. 2013. Mata Atlântica. http:// www.mma.gov.br/biomas/mata-atlantica (último acesso em 19/08/2012).

BRAZ, D.M., MOURA, M.V.L.P. \& ROSA, M.M.T. 2004. Chave de identificação para as espécies de dicotiledôneas arbóreas da Reserva Biológica do Tinguá-RJ, com base em caracteres vegetativos. Acta Bot. Bras. 18(2):225-240. http://dx.doi.org/10.1590/S010233062004000200003

BRIDSON, D. \& FORMAN, L. 2004. The Herbarium Handbook. The Royal Botanic Garden, Kew.

CÂMARA, I.G. 1991. Plano de Ação para a Mata Atlântica. São Paulo, Fundação SOS Mata Atlântica.

CAMPANILI, M. \& SCHAFFER, W.B. 2010. Mata Atlântica: patrimônio nacional dos brasileiros. MMA, Brasília.

CARDOSO, P.R. 2011. Estruturas secretoras em plantas. Instituto de Botânica, Jardim Botânico de São Paulo. http://www.biodiversidade.pgibt.ibot. sp.gov.br/Web/pdf/Estruturas_Secretoras_Poliana_Ramos_Cardoso.pdf (último acesso em 22/02/2013).

CARVALHO, P.E.R. 2003. Espécies Arbóreas Brasileiras. Embrapa, Brasília. CARVALHO, P.E.R. 2006. Espécies Arbóreas Brasileiras. Embrapa, Brasília.

CONSTANTINO, R., BRITES, R.M. CERQUEIRA, R., ESPINDOLA, E.L.G., GRELLE, C.E.V., LOPES, A.T.L., NASCIMENTO, M.T., ROCHA, O., RODRIGUES, A.A.F., SCARIOT, A., SEVILHA, A.C. \& TIEPOLO, G. 2003. Vegetação e Flora. In Fragmentação de ecossistemas: causas, efeitos sobre a biodiversidade e recomendações de políticas públicas (D.M. Rambaldi, D.A.S. Oliveira, eds.). MMA/SBF, Brasília, p.103-124.

DIONÍSIO, G.O., BARBOSA, M.R.V. \& LIMA, H.C. 2010. Leguminosas arbóreas em remanescentes florestais localizados no extremo norte da Mata Atlântica. Rev. Nordestina Biol. 19(2):15-24.

ELTINK, M., RAMOS, E., TORRES, R.B., TAMASHIRO, J.Y., GALEMBECK, E. \& KIMURA, E. 2011. Chave de identificação de espécies do estrato arbóreo da Mata Atlântica em Ubatuba (SP), com base em caracteres vegetativos. Biota Neotrop 11(2):393-405. http://dx.doi. org/10.1590/S1676-06032011000200037

ENVIRONMENT SYSTEMS RESEARCH INSTITUTE - ESRI. 2010. ArcGIS Desktop: Release 10. ESRI, Redlands.

FILARDI, F.L.R., GARCIA, F.C.P. \& OKANO, R.M.C. 2009. Caesalpinioideae (Leguminosae) lenhosas na Estação Ambiental de Volta Grande, Minas Gerais, Brasil. R. Árvore 33(6):1071-1084. http://dx.doi.org/10.1590/ S0100-67622009000600010 
FORZZA, R.C., STEHMANN, J.R., NADRUZ, M., COSTA, A. CARVALHO-JUNIOR, A. A., PEIXOTO, A.L., WALTER, B. M.T., BICUDO, C., MOURA, C.W.N., ZAPPI, D., COSTA, D.P., LLERAS, E., MARTINELLI, G., LIMA, H.C., PRADO, J., BAUMGRATZ, J.F.A., PIRANI, J.R; SYLVESTRE, L.S., MAIA, L.C., LOHMANN, L.G., PAGANUCCI, L., ALVES, M.V.S., SILVEIRA, M., MAMEDE, M.C.H., BASTOS, M.N.C, MORIM, M.P., BARBOSA, M.R., MENEZES, M., HOPKINS, M., EVANGELISTA, P.H.L; GOLDENBERG, R.M.P., SECCO, R., RODRIGUES, R.S., CAVALCANTI, T. \& SOUZA, V.C., orgs. 2013. Lista de Espécies da Flora do Brasil. Jardim Botânico do Rio de Janeiro. <http://floradobrasil.jbrj.gov.br/jabot/floradobrasil/FB115> (último acesso em 21/02/2013).

GONÇALVES, E.G. \& LORENZI, H. 2011. Morfologia vegetal: organografia e dicionário ilustrado de morfologia das plantas vasculares. 2.ed. Plantarum, Nova Odessa.

IGLESIAS, J.O.V., JUNQUEIRA, D.I., RANDO, J.G. \& MOURA, T.M. 2011 Listagem das Leguminosae - Caesalpinioideae no Parque Estadual da Serra de Caldas Novas, Goiás, Brasil. R. bras. Bioci. 9(4):421-427.

INSTITUTO BRASILEIRO DE GEOGRAFIAE ESTATÍSTICA - IBGE. 2012. Manual técnico da vegetação brasileira. 2.ed. Rio de Janeiro.

INSTITUTO BRASILEIRO DO MEIO AMBIENTE E DOS RECURSOS NATURAIS RENOVÁVEIS - IBAMA. 2010. Corredor de Santa Maria. http://www.prbiodiversidade.pr.gov.br/arquivos/File/36\%20 IBAMACORREDOR_SANTA_MARIA.pdf(último acesso 13/01/2013).

INTERNATIONAL PLANT NAMES INDEX - IPNI. 1999. 'The plant names project'. http://www.ipni.org (último acesso em 12/ mar./ 2013).

ITAIPU. 2010. Corredor de Biodiversidade. http://www.itaipu.gov.br/ meioambiente/corredor-de-biodiversidade (último acesso em 15/06/2013).

JACOMASSA, F.A.F. 2010. Espécies arbóreas nativas da mata ciliar da Bacia Hidrográfica do Rio Lajeado Tunas, na região do Alto Uruguai, RS. Biodivers. Pampeana 8(1):1-6.

LEWIS, G.P. 1987. Legumes of Bahia. The Royal Botanic Garden, Whitstasble.

LEWIS, G.P., SCHRIRE, R., MACKINDER, B. \& LOCK, M. 2005. Legumes of the World. The Royal Botanic Garden, Kew.

LIMA, H.C., QUEIROZ, L.P., MORIM, M.P., SOUZA, V.C., DUTRA, V.F., BORTOLUZZI, R.L.C., IGANCI, J.R.V., FORTUNATO, R.H., VAZ, A.M.S.F., SOUZA, E.R., FILARDI, F.L.R., VALLS, J.F.M., GARCIA, F.C.P., FERNANDES, J.M., MARTINS-DA-SILVA, R.C.V., PEREZ, A.P.F., MANSANO, V.F., MIOTTO, S.T.S., TOZZI, A.M.G.A., MEIRELES, J.E., LIMA, L.C.P., OLIVEIRA, M.L.A.A., FLORES, A.S., TORKE, B.M., PINTO, R.B., LEWIS, G.P., BARROS, M.J.F., SCHÜTZ, R., PENNINGTON, T., KLITGAARD, B.B., RANDO, J.G., SCALON, V.R., CARDOSO, D.B.O.S., COSTA, L. C., SILVA, M.J., MOURA, T.M., BARROS, L.A.V., SILVA, M.C.R., QUEIROZ, R.T., SARTORI, A.L.B., CAMARGO, R., LIMA, I.B. 2013. Leguminosae. In: Lista de Espécies da Flora do Brasil. (R. C. Forzza, J.R., Stehmann, M. Nadruz, A. Costa, A.A. Carvalho-Junior, A.L. Peixoto, B.M.T. Walter, C. Bicudo, C.W.N. Moura, D. Zappi, D.P. Costa, E. Lleras, G. Martinelli, H.C. Lima, J. Prado, J.F.A. Baumgratz, J.R. Pirani, L.S. Sylvestre, L.C. Maia, L.G. Lohmann, L. Paganucci, M.V.S. Alves, M. Silveira, M.C.H. Mamede, M.N.C. Bastos, M.P. Morim, M.R. Barbosa, M. Menezes, M. Hopkins, P.H.L. Evangelista, R.M.P. Goldenberg, R. Secco, R.S. Rodrigues, T. Cavalcanti \& V.C. Souza, orgs.). Jardim Botânico do Rio de Janeiro. http://floradobrasil.jbrj.gov.br/ (último acesso em 21/02/2013).

MARANGON, L.C., SOARES, J.J. \& E FELICIANO, A.L.P. 2003. Florística arbórea da Mata da Pedreira, município de Viçosa, Minas Gerais. R. Árvore 27(2):207-215. http://dx.doi.org/10.1590/S010067622003000200010

MElO, Y., CÓRDUlA, E., MACHADO, S.R. \& ALVES, M. 2010. Morfologia de nectários em Leguminosae senso lato em áreas de caatinga no Brasil. Acta Bot. Bras. 24(4):1034-1045. http://dx.doi.org/10.1590/ S0102-33062010000400018

MONTES, L.V., BROSEGHINI, L.P., ANDREATTA, F.S., SANT'ANNA, M.E.S., NEVES, V.M. \& SILVA, A.G. 2009. Evidências para o uso da óleo-resina de copaíba na cicatrização de ferida - uma revisão sistemática. Natureza 7(2):61- 67.
MYERS, N., MITTERMEIER, R.A., MITTERMEIER, C.G., FONSECA, G.A.B. \& KENT, J. 2000. Biodiversity hotspots for conservation priorities. Nature. 403:853-858. http://dx.doi.org/10.1038/35002501

ODUM, E.P. \& BARRET, G.W. 2008. Fundamentos de Ecologia. 5.ed. Cengage Learning, São Paulo.

PESTANA, L.T.C., ALVES, F.M. \& SARTORI, A.L.B. 2011. Espécies arbóreas da arborização urbana do centro do município de Campo Grande, Mato Grosso do Sul, Brasil. REVSBAU 6(3):1-21.

PIERI, F.A., MUSSI, M.C. \& MOREIRA, M.A.S. 2009. Óleo de copaíba (Copaifera sp.):histórico, extração, aplicações industriais e propriedades medicinais. Rev. Bras. Pl. Med. 11(4):465-472. http://dx.doi.org/10.1590/ S1516-05722009000400016

RADFORD, A.E., DICKISON, W.C., USA MASSEY, J.R. \& BELL, C.R. 1974. Vascular Plant Systematics. Harper \& Row, New York.

RAMOS, V.S., DURIGAN, G., FRANCO, G.A.D.C., SIQUEIRA, M.F. \& RODRIGUES, R.R. 2008. Árvores da Floresta Estacional Semidecidual - Guia de identificação de espécies UDUSP, Biota/Fapesp, São Paulo.

RIBEIRO, J.E.L.S., HOPKINS, M.J.G., VICENTINI, A., SOTHERS, C.A., COSTA, M.A.S., BRITO, J.M., SOUZA, M.A.D., MARTINS, L.H.P., LOHMANN, L.G., ASSUNÇ̃̃O, P.A.C.L., PEREIRA, E.C., SILVA, C.F., MESQUITA, M.R. \& PROCÓPIO, L.C. 1999. Flora da Reserva Ducke, Guia de Identificação. DFID \& INPA, Manaus.

RIBEIRO M.C., METZGER, J.P., MARTENSEN, A.C. PONZONI, F.J. \& HIROTA, M.M. 2009. The Brazilian Atlantic Forest: How much is left, and how is the remaining forest distributed? Implications for conservation. Biol. Conserv. 142(2009):1141-1153. http://dx.doi.org/10.1016/j. biocon.2009.02.021

ROLIM, S.G., IVANAUSKAS, N.M., RODRIGUES, R.R., NASCIMENTO, M.T., GOMES, J.M.L., FOLLI, D.A. \& COUTO, H.T.Z. 2006. Composição Florística do estrato arbóreo da Floresta Estacional Semidecidual na Planície Aluvial do rio Doce, Linhares, ES, Brasil. Acta Bot. Bras. 20(3):549-561. http://dx.doi.org/10.1590/S010233062006000300005

SARTORI, A.L.B. \& TOZZI, A.M.G.A. 2004. Revisão taxonômica de Myrocarpus Allemão (Leguminosae, Papilionoideae, Sophoreae). Acta Bot. Bras. 18(3):521-535. http://dx.doi.org/10.1590/S010233062004000300012

SILVA, R.R. \& TOZZI, A.M.G.A. 2012a. Papilionoideae (Leguminosae) do Planalto Residual do Urucum, oeste do Pantanal do Mato Grosso do Sul, Brasil. Hoehnea 39(1):39-83. http://dx.doi.org/10.1590/S223689062012000100003

SILVA, M.J. \& TOZZI, A.M.G.A. 2012b. Revisão taxonômica de Lonchocarpus s. str. (Leguminosae, Papilionoideae) do Brasil. Acta Bot. Bras. 26(2):357-377.

SNAK, C., TEMPONI, L.G. \& GARCIA, F.C.P. 2012. Leguminosae no Parque Ecológico Paulo Gorski, Cascavel, Paraná, Brasil. Rodriguésia 63(4):999-1017. http://dx.doi.org/10.1590/S217578602012000400016

TALORA, D.C. \& MORELLATO, P.C. 2000. Fenologia de espécies arbóreas em florestas de planície litorânea do sudeste do Brasil. Rev. Bras. Bot. 23(1):3-26. http://dx.doi.org/10.1590/S0100-84042000000100002

URBANETZ, C., TAMASHIRO, J. Y. \& KINOSHITA, L. S. 2010. Chave de identificação de espécies lenhosas de um trecho de Floresta Ombrófila Densa Atlântica, no Sudeste do Brasil, baseada em caracteres vegetativos. Biota Neotrop. 10(2):. http://www.biotaneotropica.org.br/v10n2/pt/ abstract?article+bn00910022010 (ultimo acesso em 01/03/2013).

VALÉRIO, A.F., WATZLAWICK, L.F., SAUERESSIG, D., PUTON, V. \& PIMENTEL, A. 2008. Análise da composição florística e da estrutura horizontal de uma Floresta Ombrófila Mista Montana, município de Irati, PR - Brasil. Rev. Acad., Ciênc. Agrár. Ambient. 6(2):137-147.

YAMAGUCHI, M.H. \& GARCIA, R.F. 2012. Óleo de copaíba e suas propriedades medicinais: Revisão bibliográfica. Rev. Saúde Pesq. 5(1):137-146. 
Marcon, T.R. et al.

\section{Anexo 1}

\section{Chave de identificação de Leguminosae do Corredor de Biodiversidade de Santa Maria:}

1. Folhas unifolioladas ou trifolioladas

2. Folhas unifolioladas, folíolos bilobados fundidos até próximo à região mediana da raque (forma de pata de vaca), ápice agudo e base cordata, ausência de nectário extrafloral, acúleos curvados em pares abaixo da inserção ramos, planta com odor característico Bauhinia forficata

2' Folhas trifolioladas, folíolos inteiros elípticos a oblongos, ápice acuminado e base arredondada, par de nectários extraflorais na inserção dos folíolos, acúleos retos no caule e ramos, planta sem odor característico

Erythrina falcata

1'. Folhas pinadas e/ou bipinadas com mais de três folíolos

3. Planta armada

4. Espinhos ramificados no tronco e ramos, folíolos crenados.

Gleditsia amorphoides

4'. Espinhos únicos no tronco e ramos, folíolos inteiros

5. Folhas pinadas, indumento castanho na raque, nervuras e folíolos

Machaerium nyctitans

5'. Folhas bipinadas, ausência de indumento castanho

6. Presença de nectário extrafloral no pecíolo

7. Tronco circular sem lâminas perpendiculares, acúleos na raque sempre presentes

8. Nectário extrafloral entre apenas os folíolos terminais, prolongamento na raque ausente Senegalia polyphylla

8'. Nectário extrafloral entre 3 a 6 pares de folíolos terminais, prolongamento na raque presente. Senegalia recurva

7'. Tronco cristado com lâminas perpendiculares, acúleos na raque nunca presentes Piptadenia gonoacantha

6'. Ausência de nectário extrafloral no pecíolo. Mimosa bimucronata

3'. Planta inerme

9. Folhas compostas pinadas

10. Presença de glândulas translúcidas no limbo

11. Glândulas translúcidas em forma de traços, ausência de exsudato vermelho no caule, folíolos alternos, ápice emarginado e base arredondada Myroxylon peruiferum

11'. Glândulas translúcidas em forma de pontuações, presença de exsudato vermelho no caule, folíolos subopostos, ápice arredondado, levemente retuso e base obtusa..... Copaifera langsdorffii

10’. Ausência de glândulas translúcidas no limbo

12. Folíolos alternos

13. Presença de exsudato vermelho na casca interna

14. Folíolos apicais e basais ovais, ápice acuminado e base arredondada, face abaxial com nervura central amarela evidente Machaerium paraguariense

14'. Folíolos apicais elípticos e basais ovais, ápice agudo a emarginado e base obtusa a aguda; face abaxial com nervura pouco evidente Machaerium stipitatum

13'. Ausência de exsudato vermelho na casca interna

15. Nervura central evidente na face abaxial

16. Ritidoma sem depressões e com lenticelas, folhas terminando em apêndice Pterogyne nitens

16'. Ritidoma com depressões e sem lenticelas, folhas nunca terminando em apêndice Apuleia leiocarpa

15'. Nervura central sem evidência na face abaxial 
17. Tronco circular, ramos escandentes, folíolos discolores, não mais de 10, ovais a elípticos, base obtusa, nervuras primárias partindo de pontos diferentes em ambos os lados do folíolo Dalbergia frutescens

17' Tronco acanalado, ramos eretos, folíolos concolores, sempre em número maior que 10, estreitamente elípticos, base assimétrica, nervuras primárias partindo do mesmo ponto em apenas um dos lados do folíolo. Holocalyx balansae

\section{2'. Folíolos opostos}

18. Raque alada, presença de nectários extraflorais na raque entre os pares de folíolos paripinados

19. Folíolos glabros, sem indumento e com nervura central e lateral não evidentes na face abaxial Inga marginata

19'. Folíolos pilosos, com indumento e com nervura central e lateral evidentes na face abaxial..... Inga striata

18'. Raque não alada, ausência de nectário extrafloral na raque entre os pares de folíolos imparipinados

20. Folíolos discolores, ápice acuminado e base obtusa a arredondada

21. Folíolos apicais elípticos e basais ovais, face abaxial sem nervuras laterais evidentes. Lonchocarpus cultratus

21'. Folíolos apicais ou basais variando de elíptico a oval, face abaxial com nervuras laterais evidentes Dahlstedtia muehlbergiana

20’. Folíolos concolores, ápice agudo e base assimétrica. Cassia leptophylla

9'. Folhas compostas bipinadas

22. Presença de nectário extrafloral no pecíolo

23. Coloração da casca interna vermelha a rosa

24. Ritidoma com lenticelas, nectário extrafloral ausente na base do pecíolo Enterolobium contortisiliquum

24'. Ritidoma sem lenticelas, nectário extrafloral presente na base do pecíolo Parapiptadenia rigida

23'. Coloração da casca interna rosada a laranjada-amarelada

25. Tronco circular sem projeções, casca interna rosada, presença de lenticelas em linhas verticais, nectário extrafloral arredondado na porção apical do pecíolo Leucaena leucocephala

25'. Tronco cristado com projeções em forma de lança, casca interna laranjada-amarelada, ausência de lenticelas, nectário extrafloral elíptico na base do pecíolo Anadenanthera peregrina var. falcata

22'. Ausência de nectário extrafloral no pecíolo

26. Coloração da casca interna esbranquiçada, presença de gema axilar globosa. Poincianella pluviosa

26'. Coloração da casca interna rosa a vermelho intenso, ausência de gema axilar globosa

27. Caules jovens clorofilados, folhas até $1 \mathrm{~m}$ de comprimento, estípula foliácea ausente. Schizolobium parahyba

27'. Caules jovens não clorofilados, folhas até $50 \mathrm{~cm}$ de comprimento, estípula foliácea presente

28. Coloração da casca interna avermelhada, indumento castanho nos ramos. Peltophorum dubium

28'. Coloração da casca interna esbranquiçada, indumento claro nos ramos Calliandra foliolosa 